\title{
Ethanedithiol Treatment of Solution-Processed ZnO Thin Films: Controlling the Intragap States of Electron Transporting Interlayers for Efficient and Stable Inverted Organic Photovoltaics
}

Sai Bai, Yizheng Jin, Xiaoyong Liang, Zhizhen Ye, Zhongwei Wu, Baoquan Sun, Zaifei Ma, Zheng Tang, Jianpu Wang, Uli Wuerfel, Feng Gao and Fengling Zhang

\section{Linköping University Post Print}

\section{Tweet}

N.B.: When citing this work, cite the original article.

Original Publication:

Sai Bai, Yizheng Jin, Xiaoyong Liang, Zhizhen Ye, Zhongwei Wu, Baoquan Sun, Zaifei Ma, Zheng Tang, Jianpu Wang, Uli Wuerfel, Feng Gao and Fengling Zhang, Ethanedithiol Treatment of Solution-Processed ZnO Thin Films: Controlling the Intragap States of Electron Transporting Interlayers for Efficient and Stable Inverted Organic Photovoltaics, 2015, ADVANCED ENERGY MATERIALS, (5), 5, 1401606.

http://dx.doi.org/10.1002/aenm.201401606

Copyright: Wiley-VCH Verlag

http://www.wiley-vch.de/publish/en/

Postprint available at: Linköping University Electronic Press

http://urn.kb.se/resolve?urn=urn:nbn:se:liu:diva-116817 
DOI: 10.1002/aenm.((please add manuscript number))

Submitted to

Article type: Full Paper

Ethanedithiol Treatment on Solution-Processed ZnO Thin Films: Controlling The Intragap States of Electron Transporting Interlayers for Efficient and Stable Inverted Organic Photovoltaics

Sai Bai, ${ }^{1}$ Yizheng Jin, ${ }^{1 *}$ Xiaoyong Liang, ${ }^{1}$ Zhizhen Ye, ${ }^{1}$ Zhongwei $W u,{ }^{2}$ Baoquan Sun, ${ }^{2 *}$ Zaifei Ma, ${ }^{3}$ Zheng Tang, ${ }^{3}$ Jianpu Wang, ${ }^{4}$ Uli Würfel,,${ }^{5,6}$ Feng Gao, ${ }^{3 *}$ and Fengling Zhang ${ }^{3}$

Dr. S. Bai, Dr. Y. Jin, X. Liang, Prof. Z.Ye,

1 State Key Laboratory of Silicon Materials, Department of Materials Science and Engineering, Cyrus Tang Center for Sensor Materials and Application, and Center for Chemistry of High-Performance and Novel Materials, Zhejiang University, Hangzhou 310027, China

E-mail: yizhengjin@zju.edu.cn

Z. Wu, Prof. B. Sun

2 Jiangsu Key Laboratory for Carbon-Based Functional Materials \& Devices, Institute of Functional Nano \& Soft Materials (FUNSOM), Soochow University,

199 Ren'ai Road, Suzhou 215123, China

E-mail:bqsun@suda.edu.cn

Dr. Z. Ma, Dr. Z. Tang, Dr. F. Gao, Dr. F. Zhang3

${ }^{3}$ Department of Physics, Chemistry and Biology (IFM), Linköping University, SE-581 83

Linköping, Sweden

E-mail:fengga@ifm.liu.se

Prof. J. Wang

${ }^{4}$ Institute of Advanced Materials, Nanjing Tech University, Nanjing 210009, China

Dr. U. Würfel

5 Fraunhofer Institute for Solar Energy Systems ISE, Heidenhofstr. 2, 79110 Freiburg, Germany

Dr. U. Würfel

${ }^{6}$ Materials Research Centre FMF, University of Freiburg,

Stefan-Meier-Str. 21, 79104 Freiburg, Germany

Keywords: organic solar cells, $\mathrm{ZnO}$ thin film, electron transporting interlayers, intragap states, molecular passivation 


\section{Abstract}

The surface defects of solution-processed $\mathrm{ZnO}$ films lead to various intragap states. When the solution-processed $\mathrm{ZnO}$ films are used as electron transport interlayers (ETLs) in inverted organic solar cells, the intragap states act as interfacial recombination centers for photogenerated charges and thereby degrade the device performance. Here we demonstrate a simple surface-passivation method based on ethanedithiol (EDT) treatment, which effectively removes the surface defects of the $\mathrm{ZnO}$ nanocrystal films by forming zinc ethanedithiolates. The surface passivation by EDT treatment modulates the intragap states of the $\mathrm{ZnO}$ films and introduces a new intragap band. When the EDT treated $\mathrm{ZnO}$ nanocrystal films are used as ETLs in inverted organic solar cells, both the power conversion efficiency and stability of the devices are improved. Our control studies show that the solar cells with EDT treated ZnO films exhibit reduced charge recombination rates and enhanced charge extraction properties. These features are consistent with the fact that the modulation of the intragap states results in reduction of interfacial recombination as well as the improved charge selectivity and electron transport properties of the ETLs. We further demonstrate that the EDT treatment based passivation method can be extended to $\mathrm{ZnO}$ films deposited form Sol-gel precursors. Our study provide an excellent example that advances on the surface chemistry, together with new understanding on the electronic properties of interfacial materials are critical for improving the performance of organic solar cells. 


\section{Introduction}

Submitted to MATERIAS

Bulk heterojunction organic photovoltaics (OPVs) are attractive for low-cost energy harvesting due to the possibility of employing high throughput solution-processable fabrication techniques and the compatibility with large-area and flexible plastic substrates. ${ }^{[1-4]}$ OPVs with an inverted structure have been proposed to improve the long-term stability. ${ }^{[5,6]}$ In this device configuration, the bottom transparent electrodes are modified by interlayers with low work function, serving as electron-transporting interlayers (ETLs). ${ }^{[7-10]} \mathrm{ZnO}$ is an attractive material for ETL applications due to its appealing properties such as excellent visible transparency, high electron mobility, environmentally friendly nature and ease of fabrication. ${ }^{[10,11]}$ A variety of low-temperature and solution-based methods by using Sol-gel precursors or colloidal nanocrystals to deposit ZnO ETLs have been demonstrated. ${ }^{[10-13]}$

Despite the successes of applying solution-processed ZnO ETLs in inverted OPVs, a major challenge lies in how to control the intragap states induced by surface defects. ${ }^{[14,15]}$ Lowtemperature and solution-processed ZnO ETLs generally have high densities of surface defects such as dangling bonds and surface groups, introducing various intragap energy levels. These intragap states act as recombination centers for photo-generated charge carriers, causing significant photocurrent loss and degrading the charge selectivity of cathode contacts. ${ }^{[15-17]}$ Moreover, surface defects of $\mathrm{ZnO}$ thin films are known to be sensitive to adsorption/desorption of oxygen and water molecules at ambient conditions, which may influence the long-term stability of ZnO ETLs and thereby the stability of OPV devices. ${ }^{[18]}$

A few strategies have been developed to passivate the surface defects of solution-processed ZnO ETLs. ${ }^{[14,16,19-23]}$ For example, employing self-assembled monolayers (SAMs) on top of ZnO films can avoid the direct contact between ETLs and active layers. The introduction of SAMs may result in formation of interfacial dipoles that favor electron extraction. ${ }^{[16,20]}$ However, the defect states in bulk ZnO ETLs cannot be effectively passivated by this 
approach. The fabrication of large-area, dense and compact SAMs, which are resistant to subsequent solution-processing procedures, is challenging for future industrial productions. In another strategy, ZnO-polymer composite films are used as ETLs. Coordination polymers such as poly(ethylene oxide) (PEG) and poly(ethylene glycol) (PEO) are used to passivate surface defects of $\mathrm{ZnO}$ nanoparticles, leading to improved device performances. ${ }^{[21,22]}$ Nevertheless, there is a tradeoff between effective surface passivation and charge transport properties of the composite films owing to the insulating nature of coordination polymers. A facile and general approach that can effectively passivate the surface defects of lowtemperature processed $\mathrm{ZnO}$ ETLs is highly desirable and critical to fully exploit their remarkable properties for inverted OPVs.

Here we propose that the surface defects of solution-processed ZnO ETLs can be passivated by specific small molecules. An alkanethiol with bidentate coordination groups, 1,2ethanedithiol (EDT), is selected to verify this hypothesis. The effects of EDT treatment on the chemical, morphological and electrical properties of thin films based on colloidal $\mathrm{ZnO}$ nanocrystals were analyzed. The EDT-treated $\mathrm{ZnO}$ nanocrystal films were applied in inverted organic solar cells to investigate the impact of modification of intragap states of the ETLs on device performance. To explore the generality of this passivation approach, the EDT treatment was also applied to ZnO ETLs deposited from Sol-gel precursors.

\section{Results and Discussion}

\subsection{EDT Treatment on ZnO Nanocrystal Films}

EDT treatment involves simple procedures of immersing films of $\mathrm{ZnO}$ nanocrystals (Figure S1) into a solution containing EDT for $1 \mathrm{~min}$, followed by annealing in a glovebox at $150{ }^{\circ} \mathrm{C}$ for $30 \mathrm{~min}$. For the sake of simplicity, the pristine $\mathrm{ZnO}$ nanocrystal thin films are named as P$\mathrm{ZnO}$ films and the EDT-treated $\mathrm{ZnO}$ nanocrystal thin films are named as $\mathrm{E}-\mathrm{ZnO}$ films in the following text. We note that the EDT treatment has previously been demonstrated to be effective in terms of replacing the original long-chain insulating ligands of lead chalcogenide 
or cadmium chalcogenide based quantum dots, and the EDT treatment leads to improved inter-particle electronic coupling and enhanced charge transport properties of the quantum dot based films. ${ }^{[24-29]}$

Fourier transform infrared spectroscopy (FTIR) analyses on the P-ZnO films reveal the presence of hydroxyl groups and carboxylate groups. As shown in Figure 1a, the broad peak at $3390 \mathrm{~cm}^{-1}$ corresponds to the hydroxyl groups and the peaks at 1560 and $1420 \mathrm{~cm}^{-1}$ correspond to the carboxylate groups. After EDT treatment, the intensities of these absorption peaks are decreased, suggesting that a large fraction of the hydroxyl and carboxylate groups have been removed. Furthermore, the characteristic stretching band of $-\mathrm{CH}_{2}$ - groups at 2920 $\mathrm{cm}^{-1}$ becomes evident, implying the binding of EDT molecules onto the surfaces of E-ZnO films. ${ }^{[26,27]}$

X-ray photoelectron spectroscopy (XPS) analyses reveal surface chemistry of the $\mathrm{ZnO}$ nanocrystal films. The survey spectra of the $\mathrm{P}-\mathrm{ZnO}$ and $\mathrm{E}-\mathrm{ZnO}$ films are shown in Figure $1 \mathrm{~b}$. The most significant change due to EDT treatment is the emergence of the sulfur peaks (inset of Figure 1b). The S 2p peak located at $163.2 \mathrm{eV}$ with a shoulder at $164.3 \mathrm{eV}$ (Figure S2) indicates that EDT molecules were covalently bonded onto the surfaces of $\mathrm{ZnO}$ nanocrystals, forming zinc thiolates. ${ }^{[30-32]}$ Figure $1 \mathrm{c}$ shows the $\mathrm{O}$ 1s core level spectra, which can be deconvoluted into two peaks. The lower-binding-energy peak is associated with the oxygen atoms in a $\mathrm{ZnO}$ matrix, i.e. $\mathrm{O}-\mathrm{Zn}$ bonding. The higher-binding-energy peak is attributed to the oxygen-deficient defects, such as oxygen vacancies and hydroxyl O-H groups. ${ }^{[11,33]}$ After EDT treatment, the relative intensity of the higher-binding-energy component significantly decreased, suggesting that the oxygen-deficient defects in the $\mathrm{ZnO}$ films are largely removed. These results, together with the FTIR analyses indicate the protonation of thiols to displace the surface groups and passivation of the surface defects. Furthermore, the $\mathrm{Zn} 2 \mathrm{p}_{3 / 2}$ peak shifts towards lower binding energy by $0.2 \mathrm{eV}$ after EDT treatment (Figure 1d). This shift reflects 
the higher electron densities around the zinc atoms. The more negative oxidation state of the zinc ions is consistent with the formation of $\mathrm{Zn}-\mathrm{S}$ bonds, which replaces the original $\mathrm{Zn}-\mathrm{O}$ bonds of the hydroxyl groups or carboxylate groups. ${ }^{[31]}$ A quantitative depth-profile study on the E-ZnO films was carried out (Figure 1e). With the prolonged sputter time, the atomic ratio of sulfur to zinc is kept in the range of 0.25 to 0.29 , indicating that EDT treatment effectively modified all the $\mathrm{ZnO}$ nanocrystals in the bulk films which are $\sim 85 \mathrm{~nm}$ in thickness.

The surface properties of the $\mathrm{ZnO}$ nanocrystal thin films were characterized by contact angle measurements and atomic force microscopy (AFM). As illustrated in Figure S3, the static contact angles of water on the $\mathrm{ZnO}$ films increased from $41^{\circ}$ to $53^{\circ}$ upon the EDT treatment. The fact that the E-ZnO films are more hydrophobic agrees with the EDT treatment induced surfaces with $-\mathrm{CH}_{2}-\mathrm{CH}_{2}$ - groups. AFM measurements show that the $\mathrm{E}-\mathrm{ZnO}$ and $\mathrm{P}-\mathrm{ZnO}$ films have comparable root-mean-square (RMS) surface roughness of $\sim 5 \mathrm{~nm}$ (Figure S4). The topological images and the corresponding phase images, however, reveal significantly different features. For the P-ZnO films, large domains with sizes of 50-100 nm, due to sintering of small primary particles during the annealing procedure, were observed. In contrast, the E-ZnO films exhibit much smaller domains with sizes of less than $10 \mathrm{~nm}$. We suggest that surface passivation by EDT molecules leads to nanocrystal surfaces with $-\mathrm{CH}_{2}$ $\mathrm{CH}_{2}$ - groups. Such chemically inert surfaces prevent the growth of the oxide domains at elevated temperatures.

\subsection{P3HT:PC61BM Inverted Solar Cells Based on EDT Treated ZnO Nanocrystal Films}

The E-ZnO films were applied as ETLs in OPVs with an inverted device structure of ITO/ZnO/poly(3-hexylthiophene) (P3HT): [6-6]-phenyl-C61-butyric acid methyl ester $\left(\mathrm{PC}_{61} \mathrm{BM}\right) / \mathrm{MoO}_{\mathrm{x}} / \mathrm{Ag}$ (Figure 2a). Devices with $\mathrm{P}-\mathrm{ZnO}$ films as ETLs were also fabricated. The current density-voltage $(\mathrm{J}-\mathrm{V})$ and external quantum efficiency (EQE) characteristics of the representative devices are shown in Figure $2 \mathrm{~b}$ and Figure 2c. The corresponding electrical 
output parameters are summarized in Table 1. The results show that upon EDT treatment, the devices exhibit higher PCEs and greater EQE values over the entire photo-responsive spectral range. For the devices with $\mathrm{E}-\mathrm{ZnO}$ films, an average PCE of $4.8 \%$ was obtained. A champion device exhibited an open circuit voltage $\left(\mathrm{V}_{\mathrm{OC}}\right)$ of $0.61 \mathrm{~V}$, a short current density $\left(\mathrm{J}_{\mathrm{SC}}\right)$ of 11.88 $\mathrm{mA} / \mathrm{cm}^{2}$ and a fill factor (FF) of 0.71 , leading to a PCE of $5.1 \%$. We highlight that, the FF of 0.71 is one of the highest values reported in literature for $\mathrm{P} 3 \mathrm{HT}: \mathrm{PC}_{61} \mathrm{BM}-$ based inverted solar cells, revealing the excellent charge extraction properties of this device. The control devices based on P-ZnO ETLs exhibit a relative low average PCE of $3.8 \%$. As shown in Figure 2d, the ambient stability of the devices with E-ZnO ETLs is also significantly improved. For unencapsulated $\mathrm{P} 3 \mathrm{HT}: \mathrm{PC}_{61} \mathrm{BM}$ devices, the PCE remained $90 \%$ of the original value after being stored in dark and under ambient conditions for 30 days. In contrast, the PCE of the control device with P-ZnO ETLs degraded to $\sim 60 \%$ of the original value under the same conditions.

To understand the origin of the improved device performance, the $\mathrm{P} 3 \mathrm{HT}: \mathrm{PC}_{61} \mathrm{BM}$ inverted devices were characterized by a number of electrical techniques. First, transient photo-voltage (TPV) measurements indicate that the devices with E-ZnO ETLs exhibit reduced charge recombination rates and enhanced charge extraction characteristics. TPV measurements evaluate the charge carrier decay dynamics under an extraction electric field, providing a direct method to probe the charge populations and charge recombination in a solar cell. ${ }^{[34,35]}$ We carried out TPV measurements under different light intensities, which resulted in $\mathrm{V}_{\mathrm{OC}}$ ranging from 0.40 to $0.61 \mathrm{~V}$. The carrier lifetime at each $\mathrm{V}_{\mathrm{OC}}$ was derived from the exponentially fitting of the TPV curves. The capacitance (C) was determined using a procedure of differential charging. The steady-state carrier concentration was obtained by integrating $\mathrm{C}$ with respect to the measured $\mathrm{V}_{\mathrm{OC}}{ }^{\left[{ }^{35]}\right.}$ As shown in Figure $3 \mathrm{a}-3 \mathrm{c}$, the devices with E-ZnO ETLs exhibit longer photogenerated charge carrier lifetimes, smaller capacitance and 
reduced steady-state carrier concentrations. Therefore the devices with E-ZnO ETLs show characteristics of reduced charge recombination rates and enhanced charge extraction. ${ }^{36}$ Second, dark J-V curves show that EDT treatment significantly improved the selectivity of the cathodes. As shown in Figure 3d, the reverse saturation current for the device with E-ZnO ETL is greatly suppressed compared to the device with P-ZnO ETL while the two devices exhibit similar output current in the forward direction. Third, electron-only devices with a structure of $\mathrm{ITO} / \mathrm{ZnO} / \mathrm{P} 3 \mathrm{HT}: \mathrm{PC}_{61} \mathrm{BM} / \mathrm{LiF} / \mathrm{Al}$ were fabricated to investigate the electron transport properties of the inverted devices (Figure 3e). An increased current density for the device with E-ZnO ETLs is observed, revealing the improved electron transporting characteristics. $^{[37]}$

We suggest that for the P3HT:PC ${ }_{61} \mathrm{BM}$ devices, other factors, such as optical absorption and morphologies of active layers are not the major reasons for the improved device performance. As shown in AFM images (Figure S5), despite the slightly changed surface-wetting properties of the $\mathrm{ZnO}$ films after EDT treatment, the surface roughness and phase profiles of the active layers deposited onto the $\mathrm{E}-\mathrm{ZnO}$ or $\mathrm{P}-\mathrm{ZnO}$ films are almost identical. These results suggest that EDT treatment on the ZnO ETLs does not significantly alter the morphologies of the top blend films. Our optical modeling results (Figure S6) show that there are almost no opticalfield-dissipation difference for $550 \mathrm{~nm}$ and $600 \mathrm{~nm}$ illumination of the $\mathrm{P} 3 \mathrm{HT}: \mathrm{PC}_{61} \mathrm{BM}$ active layers in the devices with the $\mathrm{P}-\mathrm{ZnO}$ films and $\mathrm{E}-\mathrm{ZnO}$ films, respectively.

\subsection{Electronic and Molecule Model of EDT Passivated ZnO Nanocrystal Films}

Based on above analyses, we correlate the higher PCE and better stability of the devices with E-ZnO ETLs to the surface-passivation effects. We propose that surface passivation by EDT treatment leads to efficient modulation of the electronic structure and intragap states of the $\mathrm{ZnO}$ nanocrystal films. A number of spectroscopic techniques are used to verify this hypothesis. UV-Vis absorption spectra in Figure 4a show an additional broad peak in the 
range of $400-600 \mathrm{~nm}$ for the $\mathrm{E}-\mathrm{ZnO}$ films. We attribute this peak to the emergence of an intragap band with high density of states, which is confirmed by the photoluminescence (PL) spectra. As shown in Figure 4b, the PL spectrum (excitation: $310 \mathrm{~nm}$ ) of the P-ZnO film exhibits a narrow emission peak at $\sim 366 \mathrm{~nm}$ corresponding to the band-edge emission and a board peak of visible emission centered at $\sim 545 \mathrm{~nm}$, which is attributed to the defect-related emission. ${ }^{[14,38]}$ After EDT treatment, both the visible emission and the band-edge emission are almost completely quenched. We note that a similar PL quenching phenomenon was observed for the dodecanethiol modified $\mathrm{ZnO}$ nanocrystal films. ${ }^{[39]}$ The quenching of $\mathrm{PL}$ is consistent with the introduction of a new intragap band that acts as an efficient non-radiative decay channel.

Ultraviolet photoelectron spectroscopy (UPS) measurements provide further information on the band structure of the $\mathrm{ZnO}$ films. As shown in Figure 4c, the work function for the $\mathrm{P}-\mathrm{ZnO}$ and $\mathrm{E}-\mathrm{ZnO}$ films was determined to be 3.7 and $4.1 \mathrm{eV}$, respectively. For the $\mathrm{P}-\mathrm{ZnO}$ films, the position of the valence band edge relative to the Fermi level is $3.6 \mathrm{eV}$. This fact suggests that the Fermi level is close to the conducting band edge, implying a high electron concentration induced by the defects, such as oxygen vacancies. ${ }^{[40]}$ After EDT treatment, the position of the valence band edge relative to the Fermi level decreases to $2.4 \mathrm{eV}$. Therefore the Fermi level is moving towards the center of the band gap, suggesting a significant reduction of electron concentration.

Furthermore, the passivation of the surface defects makes the $\mathrm{ZnO}$ nanocrystal films less susceptible to oxygen and water molecules in the environment. Figure 4d shows the timeresolved photocurrent decay of the $\mathrm{ZnO}$ nanocrystal films in response to pulsed UV illuminations. The photocurrent decay of $\mathrm{ZnO}$ films is largely controlled by the adsorption/desorption of water or oxygen molecules. ${ }^{[18]}$ Given that the experiments were 
conducted at the same ambient conditions, a slower decay process for the E-ZnO film suggests that the available absorption/desorption sites are decreased.

The above information allows us to conclude that the intragap states of the $\mathrm{ZnO}$ nanocrystals were effectively modified by the EDT treatment, introducing a new intragap band (Figure 5a and Figure 5b). In this scenario, the various surface defects including surface groups, such as hydroxyl groups and carboxylate groups, and dangling bonds were passivated by the formation of zinc ethanedithiolates (Figure 5c). The EDT treatment induced intragap band facilitates electron transport in the ETLs while the intragap states induced by the surface defects acts as trapping centers (Figure 5a and Figure 5b). Therefore EDT treatment largely eliminates the recombination centers at the $\mathrm{ZnO}$ /active layer interfaces and improves the electron transport properties of the bulk $\mathrm{ZnO}$ films. In consequence, EDT treatment suppresses the interfacial bimolecular recombination of the trapped electrons and photogenerated holes, enhances the charge selectivity of the cathode contact and improves the charge extraction properties of the devices. In addition, the E-ZnO films are less susceptible to oxygen and water molecules. This change greatly improves the ambient stability of the ZnO ETLs and thereby the stability of the inverted devices.

Another issue worth discussing is the effect of work-function change caused by the EDT treatment. In general, the work function of the ETLs should match the quasi-Fermi potential of the acceptor material under working conditions. When Fermi-level pinning occurs, the built-in electric field and $\mathrm{V}_{\mathrm{OC}}$ are largely affected by the difference of the quasi-Fermi levels of the donor and acceptor phases instead of the work-function difference of the charge transport interlayers. ${ }^{[41]}$ According to a report by Fahlman and coworkers, the Fermi-level pinning to the negative polarons of PCBM occurs when the work function of the contacting substrate is lower than $4.3 \mathrm{eV} \cdot{ }^{[42]}$ The work function of both the E- $\mathrm{ZnO}$ films and the P-ZnO films is sufficiently low, allowing Fermi-level pinning. Therefore the increase of the work 
function of $\mathrm{E}-\mathrm{ZnO}$ films by $0.4 \mathrm{eV}$ does not degrade the built-in field of the inverted devices. $^{[43]}$

\subsection{TQ1:PC71BM Devices Using E-ZnO Interlayers and Solar Cells based on EDT Passivated Sol-gel Derived $\mathrm{ZnO}$ films}

We further applied the E-ZnO films to the fabrication of inverted solar cells based on poly[2,3-bis-(3-octyloxyphenyl) quinoxaline-5,8-diyl-alt-thiophene-2,5-diyl] (TQ1): [6,6]phenyl- $\mathrm{C}_{71}$-butyric acid methyl ester $\left(\mathrm{PC}_{71} \mathrm{BM}\right)$ blends. TQ1 is a donor material with deep highest-occupied-molecular-orbit (HOMO) level of $5.7 \mathrm{eV}^{\left[{ }^{[4]}\right]}$ As shown in Figure 6a and Table 2, the devices with E-ZnO ETLs exhibit an average PCE of $6.0 \%$. The champion device has a remarkable FF of 0.72 and a PCE of $6.3 \%$, which is the record efficiency for the inverted devices based on the TQ1: fullerene system to date. ${ }^{[21,45-46]}$ In contrast, the average PCE for control devices with $\mathrm{P}-\mathrm{ZnO}$ films, 5.0\%, is much lower. Regarding the device stability, when the devices were either stored in dark or tested upon continuous light illumination, a similar trend that the devices with E-ZnO ETLs are much better than the control devices with P-ZnO ETLs was observed (Figure 6b). Our transfer matrix optical modeling and AFM measurements show that there is also no obvious difference in the absorption and the morphologies of the active layers deposited onto the P- $\mathrm{ZnO}$ films and E$\mathrm{ZnO}$ films, respectively (see Figure S7 and Figure S8). Furthermore, electroluminescence (EL) and Fourier-transform photocurrent spectroscopy (FTPS) measurements were used to probe the population of the charge-transfer (CT) states of the TQ1 devices. From the normalized absorption and emission spectra shown in Figure S9, almost identical CT emission and EQE features of the two devices indicate that EDT treatment caused negligible influences on the donor-acceptor interfacial areas. ${ }^{[45]}$ These characterizations indicate that the improved device performance of the TQ1 devices arise from the EDT treatment of the $\mathrm{ZnO}$ nanocrystal ETLs. This result leads us to conclude that the E-ZnO films can be applied to improve the 
performance of inverted devices based on donor materials with different electronic structures. This feature is different from that of the UV-zone treatment, another widely used technique to passivate the surfaces of solution-processed $\mathrm{ZnO} \cdot{ }^{[14,47-48]}$ As reported by So and co-workers, UV-ozone treatment not only passivates the surface defects but also generates excess oxygen at the $\mathrm{ZnO}$ surfaces which may oxidize the polymers with higher-lying HOMO energies, such as P3HT, and hence degrade the device performance. ${ }^{[14]}$

Upon successful attempts of EDT passivation on $\mathrm{ZnO}$ nanocrystal films, we further extended the EDT passivation approach to the $\mathrm{ZnO}$ films deposited from Sol-gel precursors. Inverted organic solar cells based on Sol-gel derived and EDT treated $\mathrm{ZnO}$ films were fabricated using either the P3HT: $\mathrm{PC}_{61} \mathrm{BM}$ blends or TQ1: $\mathrm{PC}_{71} \mathrm{BM}$ blends as active layers. Control devices with Sol-gel derived $\mathrm{ZnO}$ films without EDT treatment were also fabricated. As shown in Figure 6c and Figure 6d, EDT treatment on the Sol-gel derived ZnO ETLs improves the PCE of the inverted devices, i.e. from $3.7 \%$ and $4.9 \%$ to $4.5 \%$ and $6.0 \%$ for $\mathrm{P} 3 \mathrm{HT}: \mathrm{PC}_{61} \mathrm{BM}$ and TQ1:PC ${ }_{71} \mathrm{BM}$ devices, respectively. The detail device parameters are summarized in Table 2. These results suggest that the EDT modification approach can be a general method to passivate the surface defects of solution-processed $\mathrm{ZnO}$ ETLs, thereby improving the performance of the resulting inverted solar cells.

\section{Conclusion}

In summary, we developed a simple and general method based on EDT treatment to passivate the surface defects and modulate the intragap states of low-temperature solution-processed $\mathrm{ZnO}$ films. By using EDT treatment on the P-ZnO films as a model system, we show that the covalently bonding of EDT molecules onto the $\mathrm{ZnO}$ surfaces by forming zinc ethanedithiolates efficiently removes various surface defects including surface groups, such as hydroxyl groups and carboxylate groups, and dangling bonds. The chemical changes are accompanied by the modification of intragap states of the $\mathrm{ZnO}$ films and the introduction of a 
new intragap band, leading to ETLs with enhanced selectivity and better electron transport properties. When the E-ZnO films are applied as ETLs in organic solar cells, the interfacial bimolecular recombination loss is minimized. Furthermore, the well-passivated surfaces of the $\mathrm{E}-\mathrm{ZnO}$ films are less susceptible to oxygen and water molecules. Therefore the inverted devices with E-ZnO films exhibited higher PCEs and improved ambient stability. We further demonstrated that the facile EDT surface passivation method can be extended to Sol-gel derived ZnO ETLs as well as inverted solar cells with different donor polymers.

Our study provides an excellent example that advances on the surface chemistry, together with new understanding on the electronic properties of interfacial materials are critical for improving the performance of organic solar cells. Considering that solution-processed $\mathrm{ZnO}$ films are used as ETLs in many optoelectronic devices, it is of interest to apply the EDT treatment based passivation method to other devices, such as hybrid perovskite solar cells and quantum-dot based solar cells.

\section{Experimental Section}

Preparation of ZnO Nanocrystal Films and Sol-gel ZnO Films: The colloidal ZnO nanocrystals were synthesized by controlled hydrolysis of zinc acetate in an alcoholic basic solution and dissolved in a mixed solvent of chloroform and methanol (3:1 by volume) as published else where. ${ }^{[18,49]}$ Patterned ITO substrates were ultrasonic cleaned with acetone, ethanol and deionized water, respectively, and then were treated in UV-ozone for $15 \mathrm{~min}$. The $\mathrm{ZnO}$ nanocrystal solution with a concentration $\sim 15 \mathrm{mg} / \mathrm{ml}$ was spin-cast at $4000 \mathrm{rpm}$ to form $\mathrm{P}-\mathrm{ZnO}$ films with thickness of $\sim 85 \mathrm{~nm}$ after annealling at $150{ }^{\circ} \mathrm{C}$ for $30 \mathrm{~min}$ in a nitrogenfilled glove box. The $\mathrm{ZnO}$ precursor solution was prepared by dissolving $15 \mathrm{mg} / \mathrm{mL}$ of $\mathrm{Zn}(\mathrm{acac})_{2}$ hydrate in absolute ethanol. The solution was stirred for $3 \mathrm{~h}$ at $50{ }^{\circ} \mathrm{C}$ and subsequently filtered through a PTFE filter $(0.22 \mu \mathrm{m})$. Sol-gel $\mathrm{ZnO}$ films were obtained by spin-coating of the precursor solution at $2000 \mathrm{rpm}$, followed by annealing at $130{ }^{\circ} \mathrm{C}$ for $1 \mathrm{~min}$. EDT Passivation of ZnO Films: Regarding the EDT treatment, the P-ZnO films were soaked 
in an acetonitrile solution containing $\operatorname{EDT}(0.1 \%$ by volume) for $1 \mathrm{~min}$. Then the films were annealed at $150{ }^{\circ} \mathrm{C}$ for $30 \mathrm{~min}$ in a nitrogen-filled glove box to obtain E-ZnO films. For Solgel $\mathrm{ZnO}$ films, a same EDT-soaking procedure was carried out and the EDT-soaked films were further annealed at $130{ }^{\circ} \mathrm{C}$ for $10 \mathrm{~min}$ in glove box.

$\mathrm{ZnO}$ Thin Films Characterization: The FTIR spectra of $\mathrm{ZnO}$ nanocrystals films with and without EDT treatment were recorded on a Bruker Tensor 27 spectrophotometer. XPS and UPS spectra were collected on a Thermo ESCALAB 250 equipment in an ultra high vacuum chamber with a vacuum $<10^{-10}$ Torr. He I $(21.22 \mathrm{eV})$ radiation line from a discharge lamp, with an experimental resolution of $0.1 \mathrm{eV}$, was used in the UPS measurements. AFM images were obtained using a Veeco Multi Mode V atomic force microscopy. Contact angle measurements were carried out using a CAM 200 optical contact angle meter. UV-Vis absorption spectra were obtained using a Shimadzu UV-3600 spectrometer. Steady-state PL measurements were acquired using an Edinburgh Instruments FLS920 fluorescence spectrometer. A spectroscopic ellipsometer (J.A.Woollam M-2000) was used to determine the optical constants and thicknesses of the $\mathrm{ZnO}$ films and active layers of the solar cells.

UV Phototconduction Characterization: The UV photoconductive behaviors of the $\mathrm{P}-\mathrm{ZnO}$ and $\mathrm{E}-\mathrm{ZnO}$ films were evaluated by using a planar device configuration. ${ }^{1} \mathrm{~A} 150$-nm-thick $\mathrm{Al}$ electrode was evaporated through a shadow mask to form "T"'-shape contacts on the $\mathrm{ZnO}$ films deposited onto pre-cleaned glass substrates. The spacing between the electrodes was 200 $\mu \mathrm{m}$ and the length was $3 \mathrm{~mm}$. UV excitation was provided by a UV light-emitting diode (370 $\mathrm{nm}$ ) and focused onto the devices with a spot size of $c a .2 \mathrm{~mm}$.

Fabrication and Characterization of Inverted Organic Solar Cells: For the P3HT: $\mathrm{PC}_{61} \mathrm{BM}$ solar cells, a solution of P3HT (Rieke Metals, \#4002-E) and $\mathrm{PC}_{61} \mathrm{BM}$ purchased from Solenne (1:0.8 by weight, $15 \mathrm{mg} / \mathrm{ml}$ ) in 1, 2-dichlorobenzene was prepared by stirring for $12 \mathrm{~h}$ at 50 ${ }^{\circ} \mathrm{C}$ in a glove box. The blend solution was deposited onto the $\mathrm{ZnO}$ thin films by spin-coating 
at $700 \mathrm{rpm}$ for $18 \mathrm{~s}$, followed by a slow solvent-evaporation process. The resulting active layer, ca. $200 \mathrm{~nm}$ in thickness, was annealed at $110{ }^{\circ} \mathrm{C}$ for $12 \mathrm{~min}$ in a glove box. Inverted organic solar cells based on TQ1 donors were fabricated by spin-coating a solution of TQ1:PC ${ }_{71} \mathrm{BM}(9: 27 \mathrm{mg} / \mathrm{mL})$ in 1,2-dichlorobenzene at $650 \mathrm{rpm}$ for $60 \mathrm{~s}$ and then at $3000 \mathrm{rpm}$ for $30 \mathrm{~s}$. Bi-layer top electrodes of $\mathrm{MoO}_{\mathrm{x}} / \mathrm{Ag}(7 / 100 \mathrm{~nm})$ were deposited by thermal evaporation under a base pressure of $6 \times 10^{-7}$ Torr (Kurt J. Lesker Mini Spectra). The device area defined by the overlapping area (square) of the ITO and Ag electrodes was $7.25 \mathrm{~mm}^{2}$. J$\mathrm{V}$ characterization of the solar cells were performed with a Keithley 2400 source meter controlled by a LabVIEW program under simulated air mass (AM) $1.5 \mathrm{G}$ irradiation at 100 $\mathrm{mW} \mathrm{cm} \mathrm{cm}^{-2}$ using a Xe lamp-based solar simulator (Newport 91160). EQE measurements were performed in air based on a home made setup consisting of a Keithley 2400 Source Measure Unit and Newport monochromator.The light intensity was calibrated using a Newport standard silicon cell 91150 and corrected for spectral mismatch.

Transient Photovoltage, Electroluminescence and Fourier-Transform Photocurrent Spectroscopy: For the TPV measurements, the solar cells were connected to a digital oscilloscope (Tektronix TDS 3012C) with an input impedance of $1 \mathrm{M} \Omega$. The intensity of white light was referred here as a "light bias". The light was used to control the VOC of the devices. A laser with a wavelength of $532 \mathrm{~nm}$ was used as the optical perturbation. The pulse duration was set to $1 \mathrm{~ms}$ and the frequency to $100 \mathrm{~Hz}$. The frequency, light intensity, and pulse duration were constant, while the photocurrent transient was measured at an impedance of $50 \Omega$. FTPS spectra were measured on a Vertex 70 from Bruker optics. EL spectra were obtained with a Shamrock sr 303i spectrograph from Andor Tech., coupled to a Newton EMCCD Si array detector. 


\section{Supporting Information}

\section{Submitted to}

Supporting Information is available from the Wiley Online Library or from the author.

\section{Acknowledgements}

This work is financially supported by the National High Technology Research and Development Program of China (2011AA050520), the National Basic Research Program of China (973 Program, 2012CB932402), the National Natural Science Foundation of China (51172203), Natural Science Funds for Distinguished Young Scholar of Zhejiang Province (R4110189) and the Public Welfare Project of Zhejiang Province (2013C31057). Financial supports from Swedish Energy Agency (Energimyndigheten) and the Swedish Research Council (VR) are also greatly appreciated. F.G. acknowledges the financial support of the European Commission under a Marie Curie Intra-European Fellowship for Career Development. The authors are grateful to Clemens Veit and Martin Sessler for device fabrication and insightful discussions. Dr. Ergang Wang at Chalmers University of Technology for TQ1 materials and Prof. Olle Inganäs at Linköping University for Lab facilities are also greatly appreciated.

Received: ((will be filled in by the editorial staff))

Revised: ((will be filled in by the editorial staff)) Published online: ((will be filled in by the editorial staff)) 
[1] G. Yu, J. Gao, J. C. Hummelen, F. Wudl, A. J. Heeger, Science 1995, 270, 1789-1791.

[2] J. J. M. Halls, C. A. Walsh, N. C. Greenham, E. A. Marseglia, R. H. Friend, S. C. Moratti, A. B. Holmes, Nature 1995, 376, 498-500.

[3] G. Li, V. Shrotriya, J. Huang, Y. Yao, T. Moriarty, K. Emery, Y. Yang, Nat. Mater. 2005, 4, 864-868.

[4] J. You, L. Dou, K. Yoshimura, T. Kato, K. Ohya, T. Moriarty, K. Emery, C.-C. Chen, J. Gao, G. Li, Y. Yang, Nat. Commun. 2013, 4, 1446.

[5] F. C. Krebs, S. A. Gevorgyan, J. Alstrup, J. Mater. Chem. 2009, 19, 5442-5451.

[6] M. Jorgensen, K. Norrman, S. A. Gevorgyan, T. Tromholt, B. Andreasen, F. C. Krebs, Adv. Mater. 2012, 24, 580-612.

[7] T. Yang, M. Wang, C. Duan, X. Hu, L. Huang, J. Peng, F. Huang, X. Gong, Energy Environ. Sci. 2012, 5, 8208-8214.

[8] Y. Zhou, F. Li, S. Barrau, W. Tian, O. Inganäs, F. Zhang, Sol. Energy Mater. Sol. Cells 2009, 93, 497-500.

[9] C. E. Small, S. Chen, J. Subbiah, C. M. Amb, S.-W. Tsang, T.-H. Lai, J. R. Reynolds, F. So, Nat. Photon. 2012, 6, 115-120.

[10] S. Bai, Z. Wu, X. Xu, Y. Jin, B. Sun, X. Guo, S. He, X. Wang, Z. Ye, H. Wei, X. Han, W. Ma, Appl. Phys. Lett. 2012, 100, 203906.

[11] Y. Sun, J. H. Seo, C. J. Takacs, J. Seifter, A. J. Heeger, Adv. Mater. 2011, 23, 1679-1683.

[12] J. You, C.-C. Chen, L. Dou, S. Murase, H.-S. Duan, S. A. Hawks, T. Xu, H. J. Son, L. Yu, G. Li, Y. Yang, Adv. Mater. 2012, 24, 5267-5272.

[13] P. de Bruyn, D. J. D. Moet, P. W. M. Blom, Org. Electron. 2010, 11, 1419-1422.

[14] S. Chen, C. E. Small, C. M. Amb, J. Subbiah, T.-h. Lai, S.-W. Tsang, J. R. Manders, J. R. Reynolds, F. So, Adv. Energy. Mater. 2012, 2, 1333-1337.

[15] M. Hartel, S. Chen, B. Swerdlow, H.-Y. Hsu, J. Manders, K. Schanze, F. So, ACS Appl. 
Mater. Interfaces 2013, 5, 7215-7218.

[16] S. K. Hau, H.-L. Yip, H. Ma, A. K.-Y. Jen, Appl. Phys. Lett. 2008, 93, 233304.

[17] A. Gadisa, Y. Liu, E. T. Samulski, R. Lopez, Appl. Phys. Lett. 2012, 100, 253903.

[18] Y. Jin, J. Wang, B. Sun, J. C. Blakesley, N. C. Greenham, Nano Lett. 2008, 8, 1649-1653.

[19] Y. E. Ha, M. Y. Jo, J. Park, Y.-C. Kang, S.-J. Moon, J. H. Kim, Synth. Met. 2014, 187, $113-117$.

[20] Y. E. Ha, M. Y. Jo, J. Park, Y.-C. Kang, S. I. Yoo, J. H. Kim, J. Phys. Chem. C 2013, 117, 2646-2652.

[21] S. Shao, K. Zheng, T. Pullerits, F. Zhang, ACS Appl. Mater. Interfaces 2012, 5, 380-385.

[22] S. B. Jo, J. H. Lee, M. Sim, M. Kim, J. H. Park, Y. S. Choi, Y. Kim, S.-G. Ihn, K. Cho, Adv. Energy. Mater. 2011, 1, 690-698.

[23] S.-H. Liao, H.-J. Jhuo, Y.-S. Cheng, S.-A. Chen, Adv. Mater. 2013, 25, 4766-4771.

[24] R. Zhou, R. Stalder, D. Xie, W. Cao, Y. Zheng, Y. Yang, M. Plaisant, P. H. Holloway, K. S. Schanze, J. R. Reynolds, J. Xue, ACS Nano 2013, 7, 4846-4854.

[25] G. Konstantatos, L. Levina, A. Fischer, E. H. Sargent, Nano Lett. 2008, 8, 1446-1450.

[26] J. M. Luther, M. Law, Q. Song, C. L. Perkins, M. C. Beard, A. J. Nozik, ACS Nano 2008, $2,271-280$.

[27] J. Tang, L. Brzozowski, D. A. R. Barkhouse, X. Wang, R. Debnath, R. Wolowiec, E. Palmiano, L. Levina, A. G. Pattantyus-Abraham, D. Jamakosmanovic, E. H. Sargent, ACS Nano 2010, 4, 869-878.

[28] Y. Liu, M. Gibbs, J. Puthussery, S. Gaik, R. Ihly, H. W. Hillhouse, M. Law, Nano Lett. 2010, 10, 1960-1969.

[29] D. A. R. Barkhouse, A. G. Pattantyus-Abraham, L. Levina, E. H. Sargent, ACS Nano 2008, 2, 2356-2362.

[30] S.-Z. Deng, H.-M. Fan, M. Wang, M.-R. Zheng, J.-B. Yi, R.-Q. Wu, H.-R. Tan, C.-H. 
Sow, J. Ding, Y.-P. Feng, K.-P. Loh, ACS Nano 2009, 4, 495-505.

[31] J. Singh, J. Im, J. E. Whitten, J. W. Soares, D. M. Steeves, Langmuir 2009, 25, 9947 9953.

[32] J. Dvorak, T. Jirsak, J. A. Rodriguez, Surf. Sci. 2001, 479, 155-168.

[33] X. Q. Wei, B. Y. Man, M. Liu, C. S. Xue, H. Z. Zhuang, C. Yang, Physica B. 2007, 388, $145-152$.

[34] P. P. Boix, J. Ajuria, R. Pacios, G. Garcia-Belmonte, J. Appl. Phys. 2011, 109, 074514.

[35] C. G. Shuttle, B. O’Regan, A. M. Ballantyne, J. Nelson, D. D. C. Bradley, J. de Mello, J. R. Durrant, Appl. Phys. Lett. 2008, 92, 093311.

[36] G. Garcia-Belmonte, P. P. Boix, J. Bisquert, M. Sessolo, H. J. Bolink, Sol. Energy Mater. Sol. Cells 2010, 94, 366-375.

[37] S. Liu, K. Zhang, J. Lu, J. Zhang, H.-L. Yip, F. Huang, Y. Cao, J. Am. Chem. Soc. 2013, $135,15326-15329$.

[38] V. Ischenko, S. Polarz, D. Grote, V. Stavarache, K. Fink, M. Driess, Adv. Funct. Mater. 2005, 15, 1945-1954.

[39] M. A. Garcia, J. M. Merino, E. Fernández Pinel, A. Quesada, J. de la Venta, M. L. Ruíz González, G. R. Castro, P. Crespo, J. Llopis, J. M. González-Calbet, A. Hernando, Nano Lett. 2007, 7, 1489-1494.

[40] B. Ehrler, K. P. Musselman, M. L. Böhm, F. S. F. Morgenstern, Y. Vaynzof, B. J. Walker, J. L. MacManus-Driscoll, N. C. Greenham, ACS Nano 2013, 7, 4210-4220.

[41] E. L. Ratcliff, B. Zacher, N. R. Armstrong, J. Phys. Chem. Lett. 2011, 2, 1337-1350.

[42] Q. Bao, X. Liu, S. Braun, M. Fahlman, Adv. Energy. Mater. 2013, DOI:10.1002/aenm.201301272.

[43] J. Reinhardt, M. Grein, C. Bühler, M. Schubert, U. Würfel, Adv. Energy. Mater. 2014, DOI:10.1002/aenm.201400081. 


\section{Submitted to}

[44] E. Wang, L. Hou, Z. Wang, S. Hellström, F. Zhang, O. Inganäs, M. R. Andersson, Adv. Mater. 2010, 22, 5240-5244.

[45] Z. Tang, L. M. Andersson, Z. George, K. Vandewal, K. Tvingstedt, P. Heriksson, R. Kroon, M. R. Andersson, O. Inganäs, Adv. Mater. 2012, 24, 554-558.

[46]Z. Ma, Z. Tang, E. Wang, M. R. Andersson, O. Inganäs, F. Zhang, J. Phys. Chem. C 2012, $116,24462-24468$.

[47] J. M. Cho, S.-W. Kwak, H. Aqoma, J. W. Kim, W. S. Shin, S.-J. Moon, S.-Y. Jang, J. Jo, Org. Electron. 2014, 15, 1942-1950.

[48] P. Adhikary, S. Venkatesan, N. Adhikari, P. P. Maharjan, O. Adebanjo, J. Chen, Q. Qiao, Nanoscale 2013, 5, 10007-10013.

[49] B. Sun, H. Sirringhaus, Nano Lett. 2005, 5, 2408-2413. 

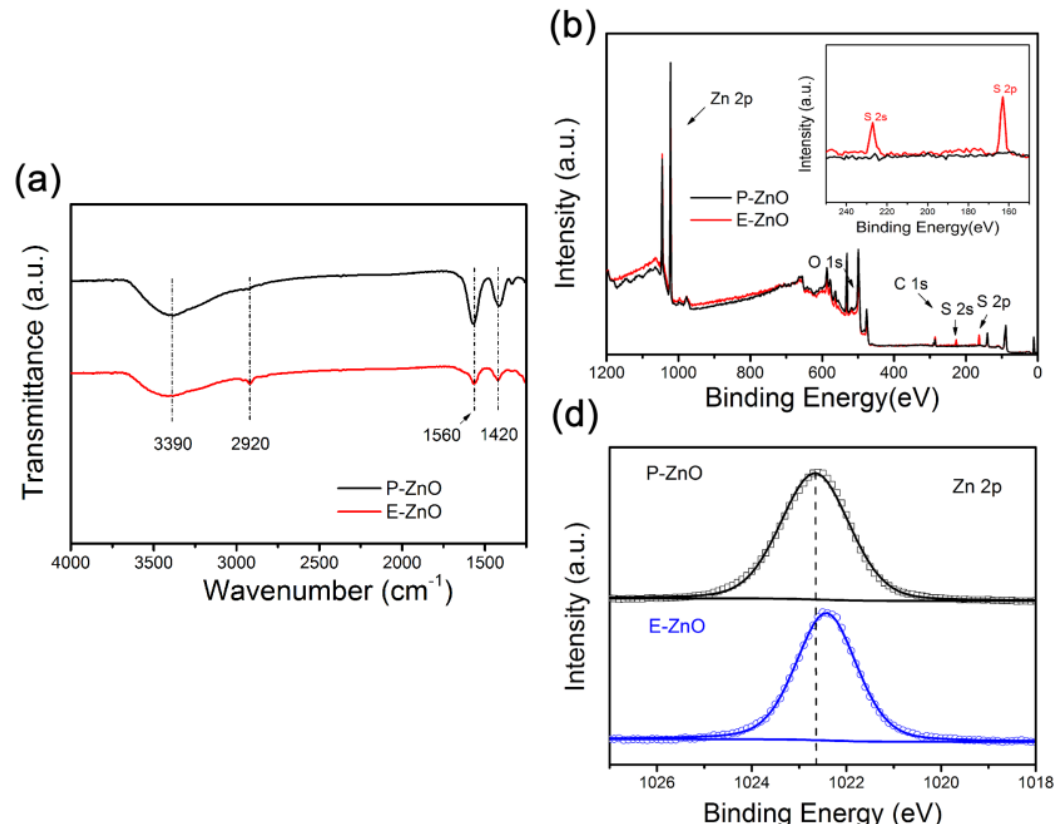

Submitted to

ENERGY

(c)

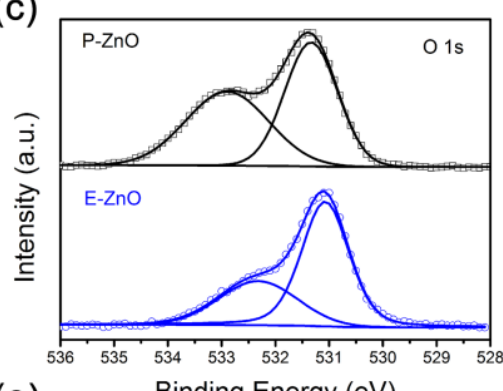

(e)

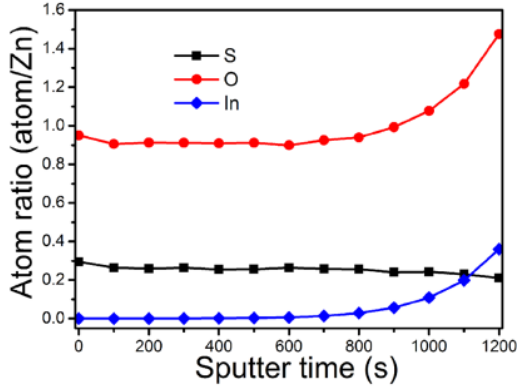

Figure 1. a) FTIR spectra of a P-ZnO film (black curve) and the corresponding E-ZnO film

(red curve) on a $\mathrm{CaF}_{2}$ substrate. b) XPS survey spectra of a P-ZnO film and an E-ZnO film. The inset is the enlarged S spectra showing the occurrence of S peaks after EDT treatment. c) O1s and (d) Zn 2p spectra of the P-ZnO film (square) and the E-ZnO film (circle). e) Depth profiles of the atom ratios of $\mathrm{S} / \mathrm{Zn}, \mathrm{O} / \mathrm{Zn}$ and $\mathrm{In} / \mathrm{Zn}$ in $\mathrm{E}-\mathrm{ZnO}$ film. 
(a)

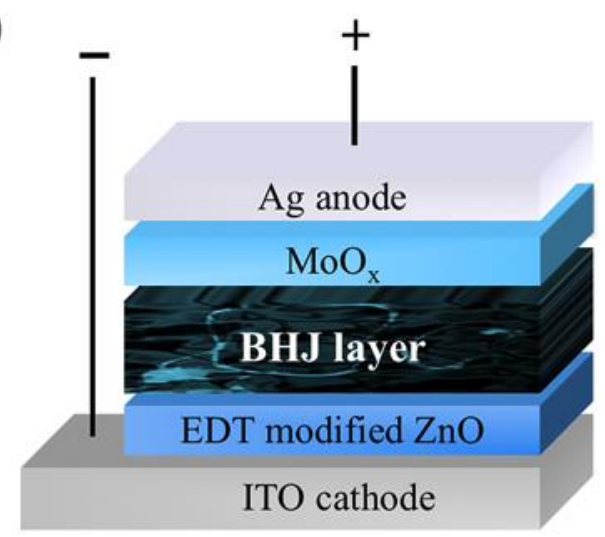

(c)

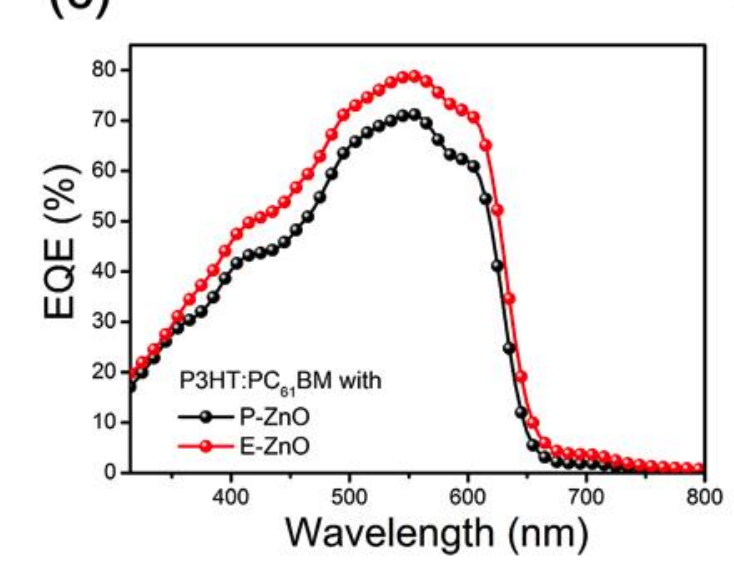

\section{ITO cathode}

(b)

Submitted to

DNANCED

ENERGY

MATERIALS
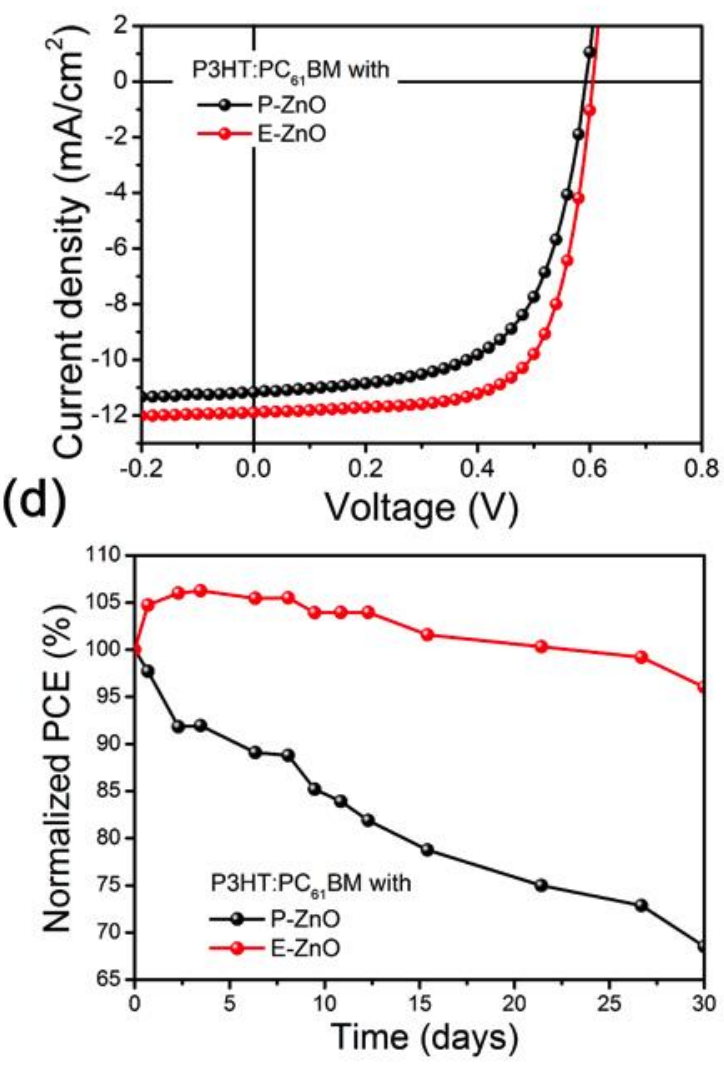

Figure 2. Inverted devices based on P3HT:PC ${ }_{61} \mathrm{BM}$ blends. a) Schematic device structure. (b) Light J-V characteristics and c) EQE curves of the devices using E-ZnO films or P-ZnO films as ETLs, respectively. d) Normalized PCE as a function of storage time (dark and ambient conditions) for devices using E-ZnO films or P-ZnO films as ETLs, respectively. 


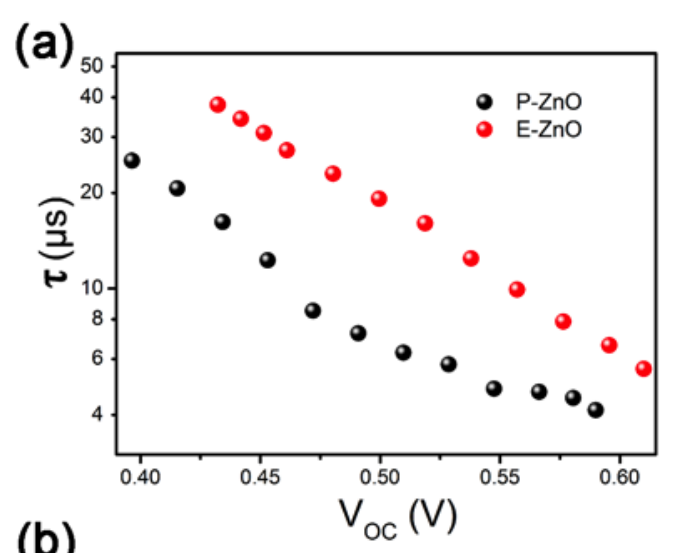

Submitted to

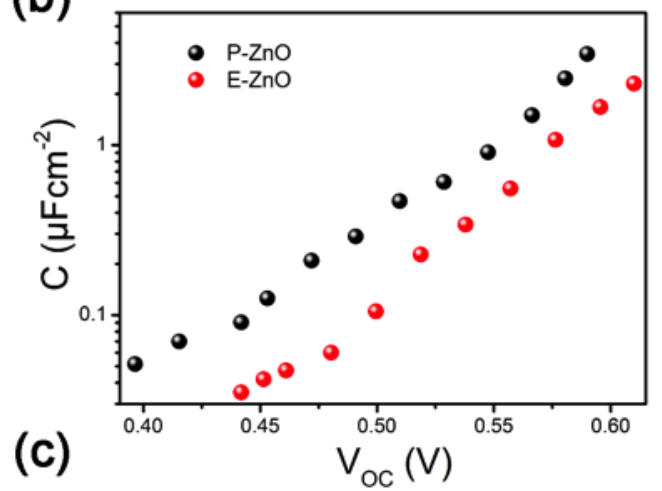

(d)

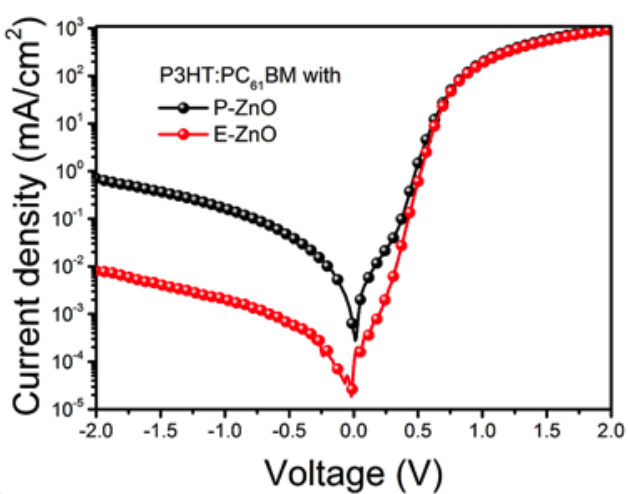

(e)
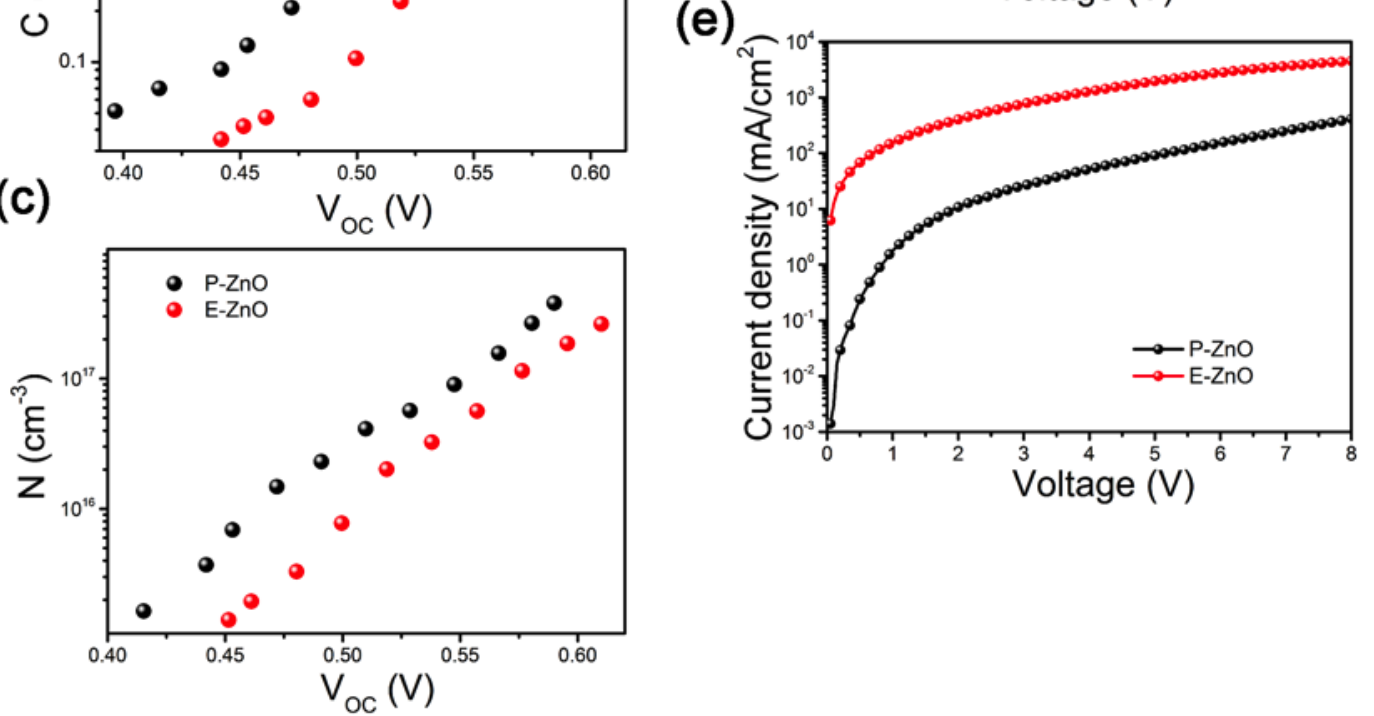

Figure 3. Analyses on the devices with $\mathrm{E}-\mathrm{ZnO}$ films or $\mathrm{P}-\mathrm{ZnO}$ films. a)-c) Charge carrier life time, differential capacitance and steady-state carrier concentration vs $\mathrm{V}_{\text {OC }}$ for inverted P3HT:PC 61 BM devices with $\mathrm{P}-\mathrm{ZnO}$ films (black) or E-ZnO films (red) as electron transport interlayers, respectively. d) Dark J-V measurements of the inverted P3HT:PC 61 BM devices with $\mathrm{P}-\mathrm{ZnO}$ films (black) or E-ZnO films (red) as electron transport interlayers, respectively. e) $\mathrm{J}-\mathrm{V}$ curves of electron-only devices (ITO/ZnO/P3HT:PC ${ }_{61} \mathrm{BM} / \mathrm{LiF} / \mathrm{Al}$ ) with $\mathrm{E}-\mathrm{ZnO}$ films or $\mathrm{P}-\mathrm{ZnO}$ films, respectively. 

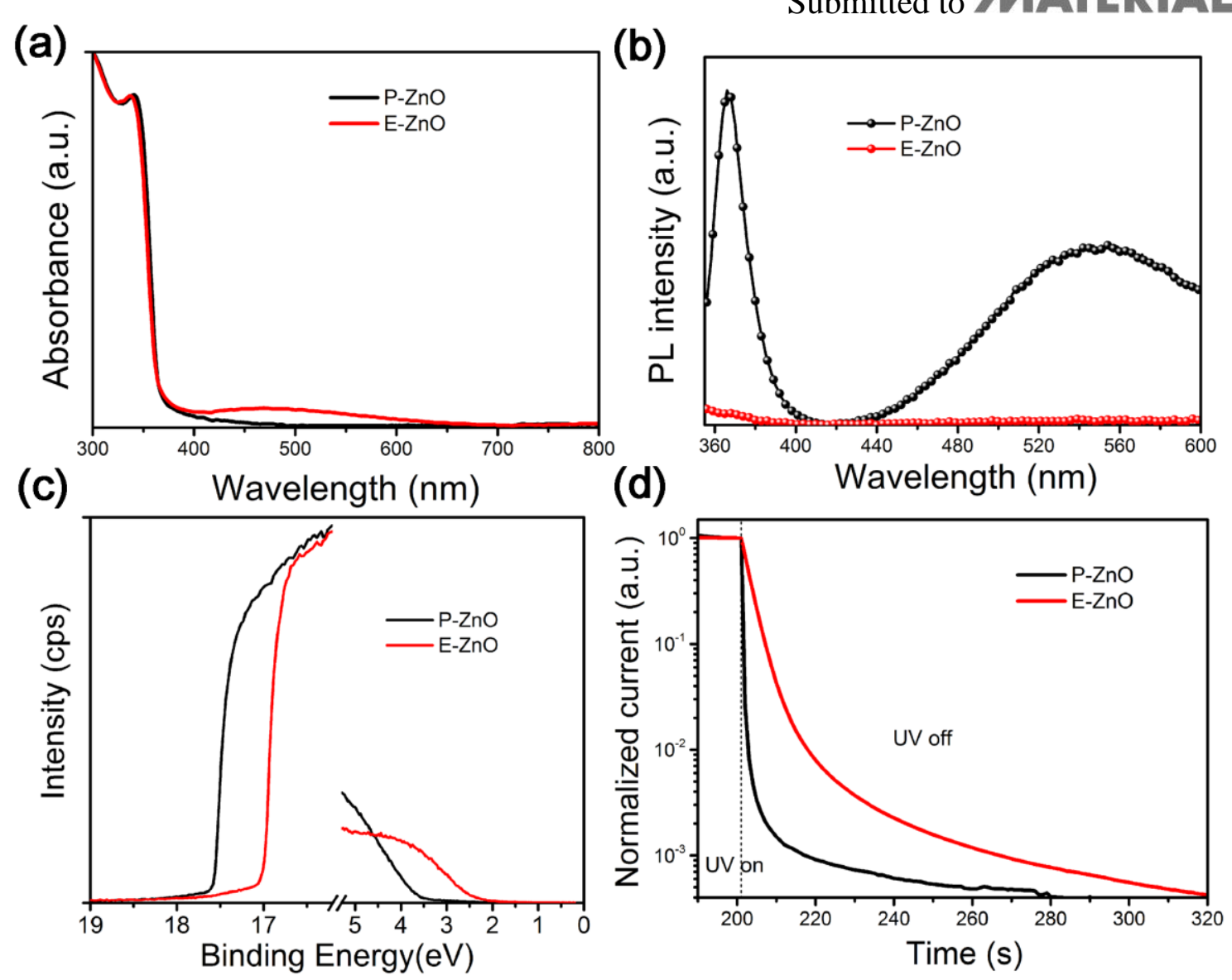

(d)

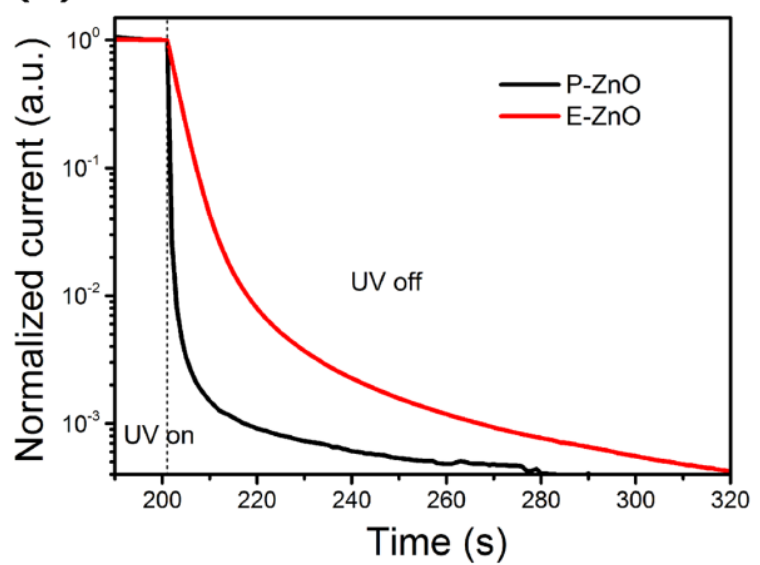

Figure 4. Electronic and electrical properties of the $\mathrm{E}-\mathrm{ZnO}$ films and the $\mathrm{P}-\mathrm{ZnO}$ films. a) Normalized UV-Vis absorption spectra, b) steady-state PL spectra excited at $310 \mathrm{~nm}$, c) UPS spectra and d) Normalized time-resolved photocurrent decay characteristics. 
(a)

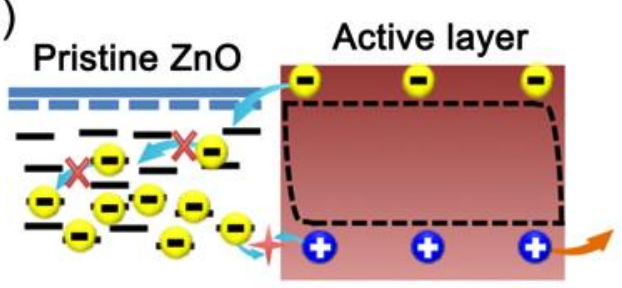

(b)

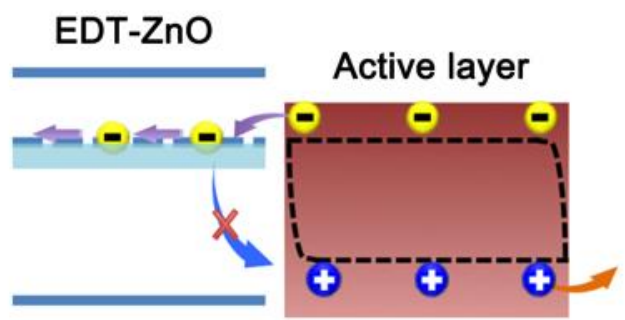

(c)

Submitted to
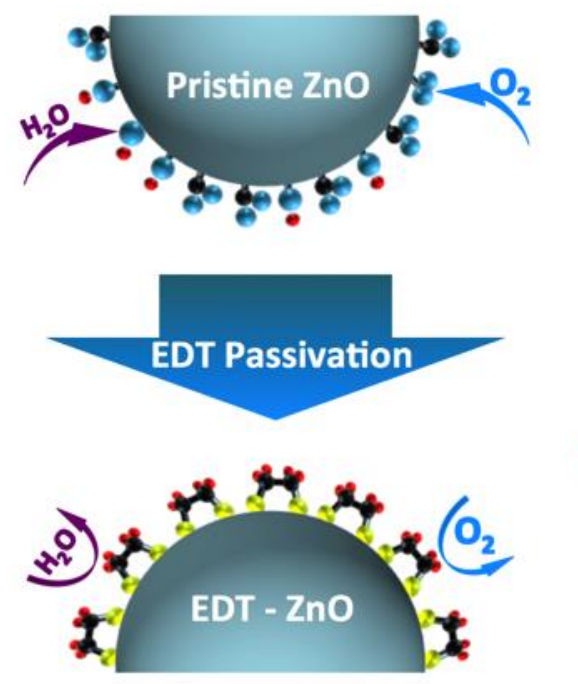

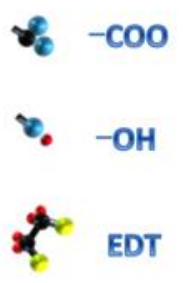

Figure 5. The impact of EDT treatment on the $\mathrm{ZnO}$ films and devices with films of $\mathrm{ZnO}$ nanocrystals as ETLs. a) The pristine $\mathrm{ZnO}$ films have various intragap states which act as recombination centers for photogenerated charges. b) After EDT treatment, the various intragap states due to surface defects are modified to a new intragap band. This new intragap band facilitates electron transport in the ETLs, thereby suppressing the interfacial bimolecular recombination and enhancing the charge extraction properties of the devices. c) Schematic representations showing that the various surface groups are removed and EDT molecules are covalently bound onto the $\mathrm{ZnO}$ surface. The excellent surface passivation makes the $\mathrm{ZnO}$ films less susceptible to oxygen and water molecules. 
(a)

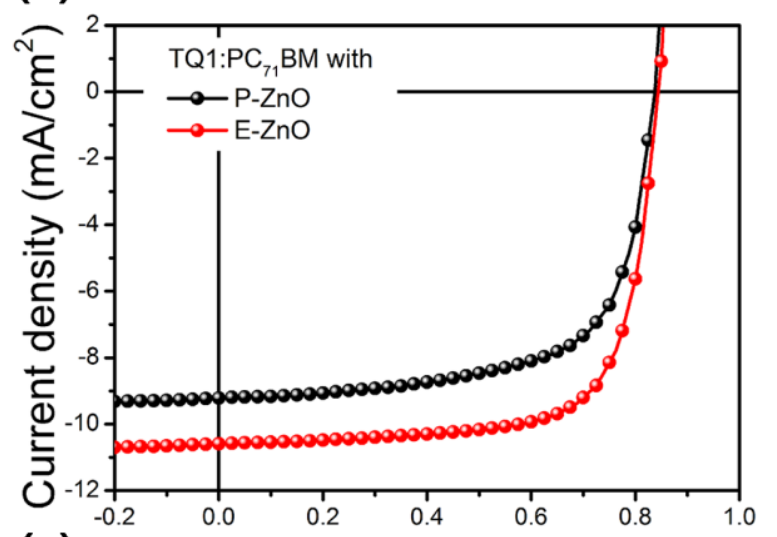

(c)

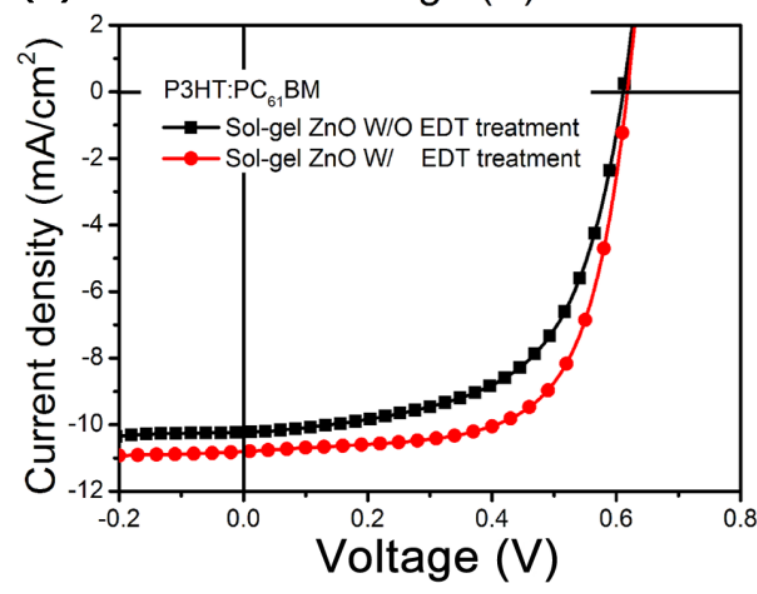

(b)

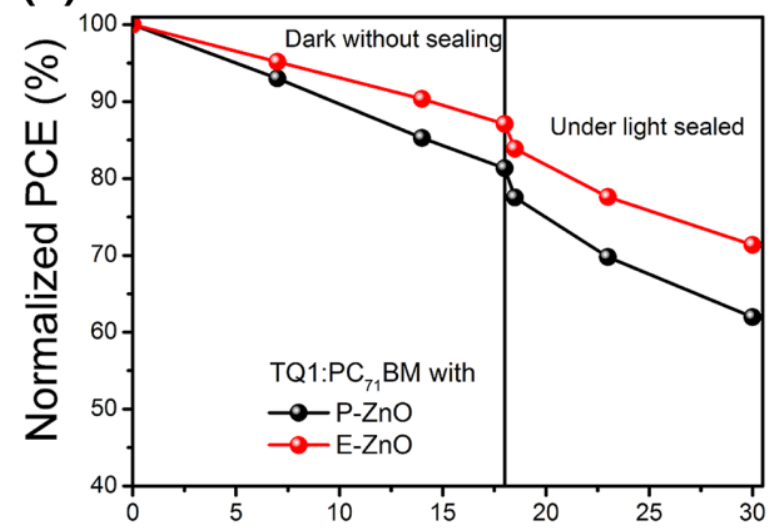

(d)

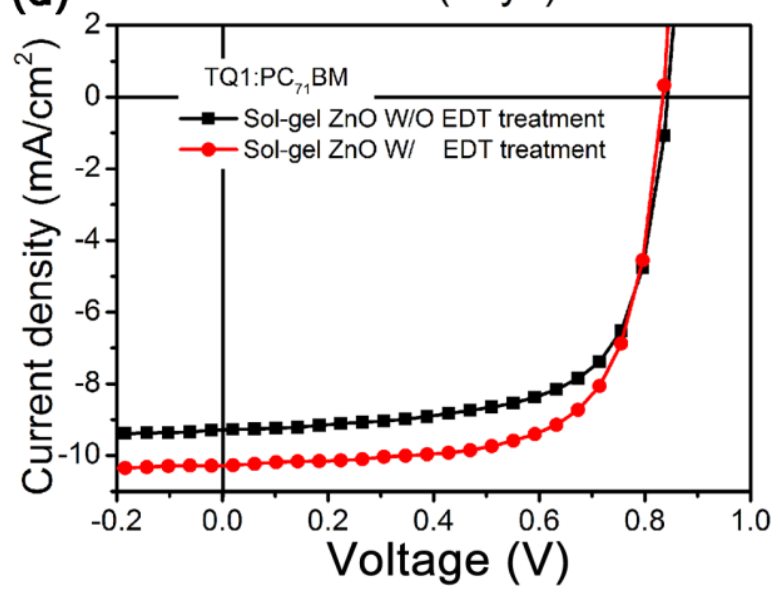

Figure 6. a) $\mathrm{J}-\mathrm{V}$ characteristics of inverted TQ1:PC ${ }_{71} \mathrm{BM}$ devices with $\mathrm{E}-\mathrm{ZnO}$ films or $\mathrm{P}-\mathrm{ZnO}$ films as ETLs, respectively. b) Normalized PCEs as a function of storage time of TQ1 based devices. The devices were stored in dark under ambient conditions (1-18 days) followed by encapsulation and then continuous illumination under $100 \mathrm{~mW} \mathrm{~cm} \mathrm{~cm}^{-2} \mathrm{AM} 1.5$ solar simulator conditions. c) Light $\mathrm{J}-\mathrm{V}$ characteristics of inverted $\mathrm{P} 3 \mathrm{HT}: \mathrm{PC}_{61} \mathrm{BM}$ devices and inverted TQ1:PC 71 BM solar cells (d) based on Sol-gel ZnO ETLs with and without EDT passivation. 


\section{ADVANCED \\ ENERGY \\ Submitted to MATERIALS}

Table 1. Device parameters of the inverted P3HT:PC ${ }_{61} \mathrm{BM}$ solar cells with E-ZnO films or P-

$\mathrm{ZnO}$ films as ETLs.

\begin{tabular}{cccccc}
\hline ETLs & $\mathrm{V}_{\mathrm{OC}}$ & $\mathrm{J}_{\mathrm{SC}}$ & $\mathrm{FF}$ & Best PCE & Average PCE \\
& $(\mathrm{V})$ & $\left(\mathrm{mA} \mathrm{cm}^{-2}\right)$ & & $(\%)$ & $(\%)$ \\
\hline P-ZnO film & 0.59 & 11.24 & 0.63 & 4.1 & $3.8 \pm 0.3$ \\
E-ZnO film & 0.61 & 11.88 & 0.71 & 5.1 & $4.8 \pm 0.3$ \\
\hline
\end{tabular}


Table 2. Summary of device parameters of the inverted $\mathrm{TQ1}: \mathrm{PC}_{71} \mathrm{BM}$ devices with $\mathrm{E}-\mathrm{ZnO}$ films or P-ZnO films as ETLs and inverted organic solar cells based on $\mathrm{ZnO}$ films deposited from Sol-gel precursors.

\begin{tabular}{|c|c|c|c|c|c|}
\hline Device configuration & $\begin{array}{l}\mathrm{V}_{\mathrm{OC}} \\
(\mathrm{V})\end{array}$ & $\begin{array}{c}\mathrm{J}_{\mathrm{SC}} \\
\left(\mathrm{mA} \mathrm{cm}^{-2}\right)\end{array}$ & $\mathrm{FF}$ & $\begin{array}{c}\text { Best PCE } \\
(\%)\end{array}$ & $\begin{array}{c}\text { Average PCE } \\
(\%)\end{array}$ \\
\hline $\mathrm{P}-\mathrm{ZnO} / \mathrm{TQ1}: \mathrm{PC}_{71} \mathrm{BM}$ & 0.84 & 9.45 & 0.67 & 5.3 & $5.0 \pm 0.3$ \\
\hline $\mathrm{E}-\mathrm{ZnO} / \mathrm{TQ} 1: \mathrm{PC}_{71} \mathrm{BM}$ & 0.85 & 10.42 & 0.72 & 6.3 & $6.0 \pm 0.3$ \\
\hline Sol-gel ZnO/P3HT:PC 61 BM & 0.61 & 10.23 & 0.59 & 3.7 & $3.3 \pm 0.4$ \\
\hline Sol-gel ZnO-EDT/P3HT:PC ${ }_{61} \mathrm{BM}$ & 0.61 & 10.98 & 0.67 & 4.5 & $4.1 \pm 0.4$ \\
\hline Sol-gel ZnO/TQ1:PC ${ }_{71} \mathrm{BM}$ & 0.83 & 9.15 & 0.65 & 4.9 & $4.5 \pm 0.4$ \\
\hline Sol-gel ZnO-EDT/TQ1:PC ${ }_{71} \mathrm{BM}$ & 0.83 & 10.35 & 0.69 & 6.0 & $5.6 \pm 0.4$ \\
\hline
\end{tabular}


The table of contents entry: A general and efficient molecular passivation strategy of solution-processed $\mathrm{ZnO}$ thin films using ethanedithiol (EDT) is developed to modify the defect and intragap states of the electron transporting interlayers in inverted organic solar cells. The efficiency and long-term air stability of devices based on EDT passivated ZnO interlayers were significant improved.

Keyword: organic solar cells, $\mathrm{ZnO}$ thin film, electron transporting interlayers, intragap states, molecular passivation

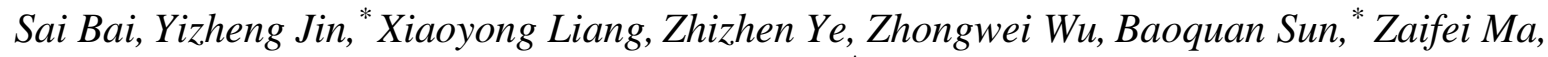
Zheng Tang, Jianpu Wang, Uli Würfel, Feng Gao, ${ }^{*}$ and Fengling Zhang

Ethanedithiol Treatment on Solution-Processed ZnO Thin Films: Controlling The Intragap States of Electron Transporting Interlayers for Efficient and Stable Inverted Organic Photovoltaics

ToC figure:

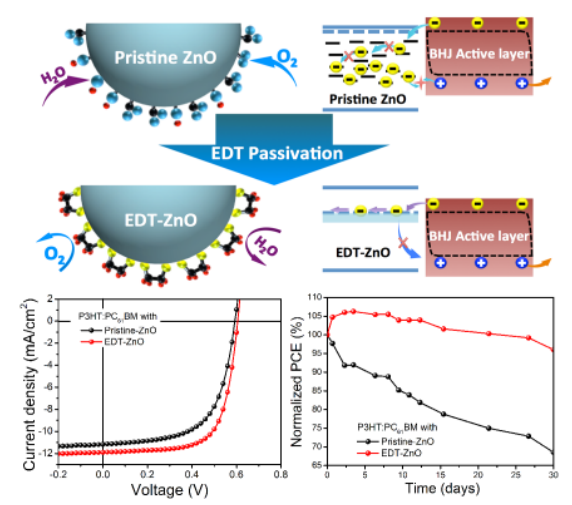




\section{Supporting Information}

Submitted to

for Adv. Energy Mater., DOI: 10.1002/aenm.((please add manuscript number))

Ethanedithiol Treatment on Solution-Processed ZnO Thin Films: Controlling The Intragap States of Electron Transporting Interlayers for Efficient and Stable Inverted Organic Photovoltaics

Sai Bai, ${ }^{1}$ Yizheng Jin, ${ }^{1 *}$ Xiaoyong Liang, ${ }^{1}$ Zhizhen Ye, ${ }^{1}$ Zhongwei Wu, ${ }^{2}$ Baoquan Sun, ${ }^{2 *}$ Zaifei

Ma, ${ }^{3}$ Zheng Tang, ${ }^{3}$ Jianpu Wang, ${ }^{4}$ Uli Würfel,,${ }^{5,6}$ Feng Gao, ${ }^{3 *}$ and Fengling Zhang ${ }^{3}$

Dr. S. Bai, Dr. Y. Jin, X. Liang, Prof. Z.Ye,

1 State Key Laboratory of Silicon Materials, Department of Materials Science and Engineering, Cyrus Tang Center for Sensor Materials and Application, and Center for Chemistry of High-Performance and Novel Materials, Zhejiang University, Hangzhou 310027, China

E-mail: yizhengjin@zju.edu.cn

Z. Wu, Prof. B. Sun

${ }^{2}$ Jiangsu Key Laboratory for Carbon-Based Functional Materials \& Devices, Institute of Functional Nano \& Soft Materials (FUNSOM), Soochow University,

199 Ren'ai Road, Suzhou 215123, China

E-mail:bqsun@suda.edu.cn

Dr. Z. Ma, Dr. Z. Tang, Dr. F. Gao, Dr. F. Zhang3

${ }^{3}$ Department of Physics, Chemistry and Biology (IFM), Linköping University, SE-581 83

Linköping, Sweden

E-mail:fengga@ifm.liu.se

Prof. J. Wang

${ }^{4}$ Institute of Advanced Materials, Nanjing Tech University, Nanjing 210009, China

Dr. U. Würfel

5 Fraunhofer Institute for Solar Energy Systems ISE, Heidenhofstr. 2, 79110 Freiburg, Germany

Dr. U. Würfel

${ }^{6}$ Materials Research Centre FMF, University of Freiburg,

Stefan-Meier-Str. 21, 79104 Freiburg, Germany 
(a)

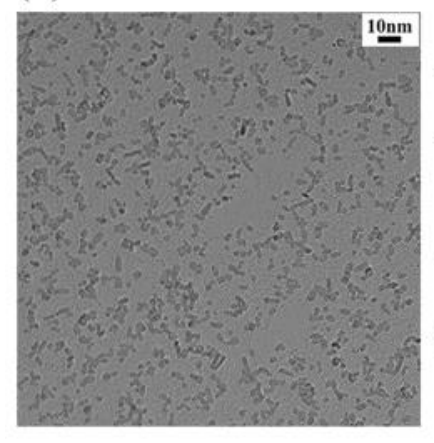

(b)

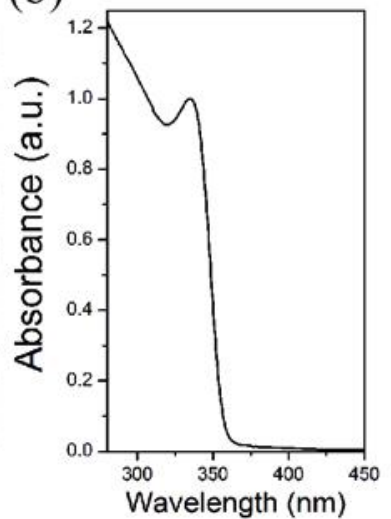

Figure S1. ZnO nanocrystals. a) Transmission electron microscopy (TEM) image and b) UVvis absorption spectrum of a solution of colloidal $\mathrm{ZnO}$ nanocrystals. 


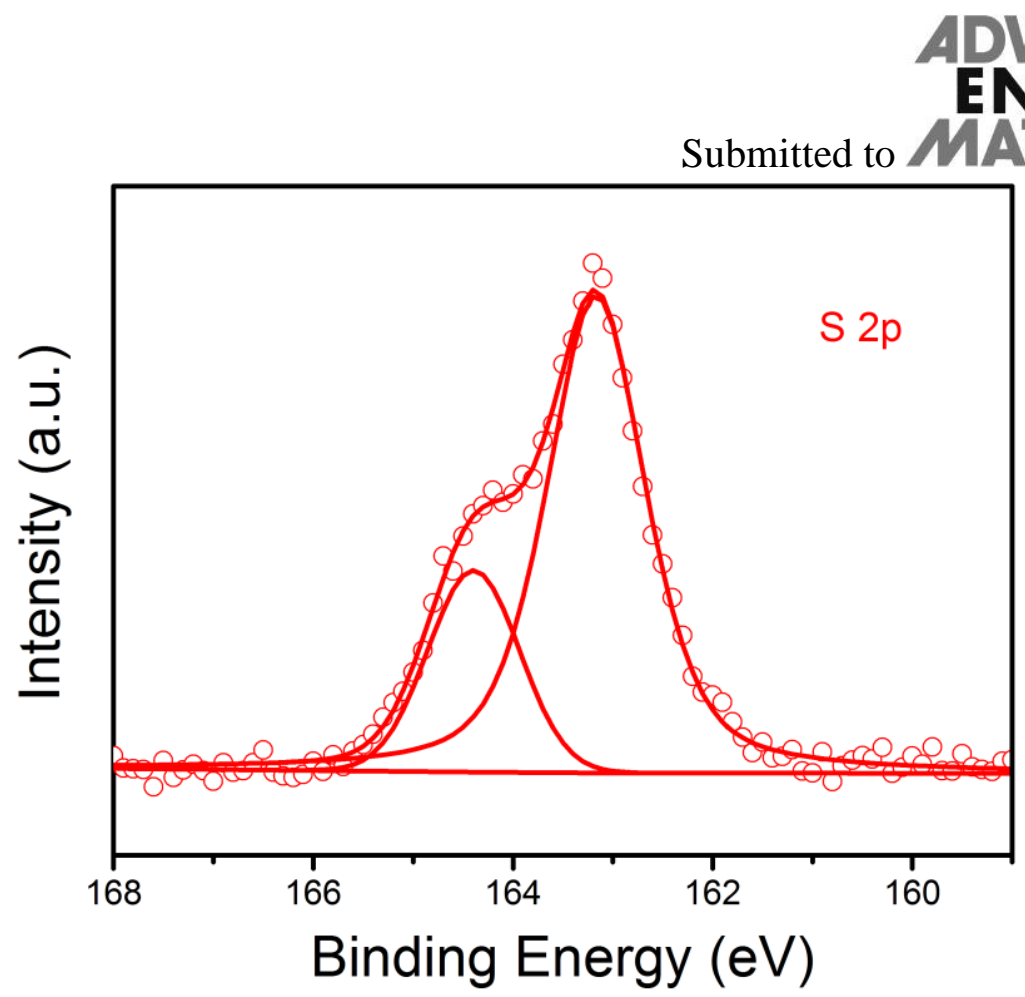

Figure S2. S 2p XPS spectrum of the E-ZnO film. 
(a) P-ZnO
CA left: $40.1^{\circ}$

CA right: $41.5^{\circ}$ (b)

\section{E-ZnO}

Submitted to

CA left: $52.6^{\circ}$

CA right: $53.1^{\circ}$

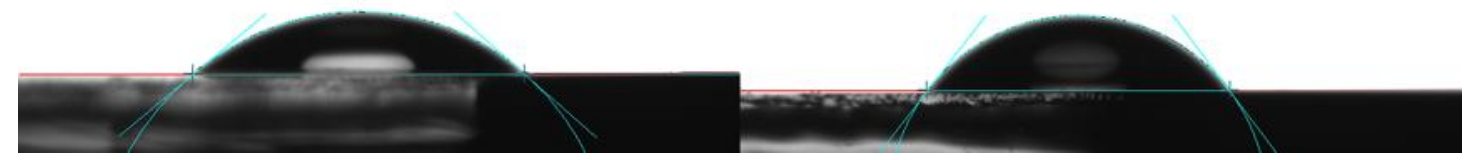

Figure S3. Images showing the contact angles of water on the $\mathrm{P}-\mathrm{ZnO}$ film (a) and the $\mathrm{E}-\mathrm{ZnO}$ film (b), respectively. 

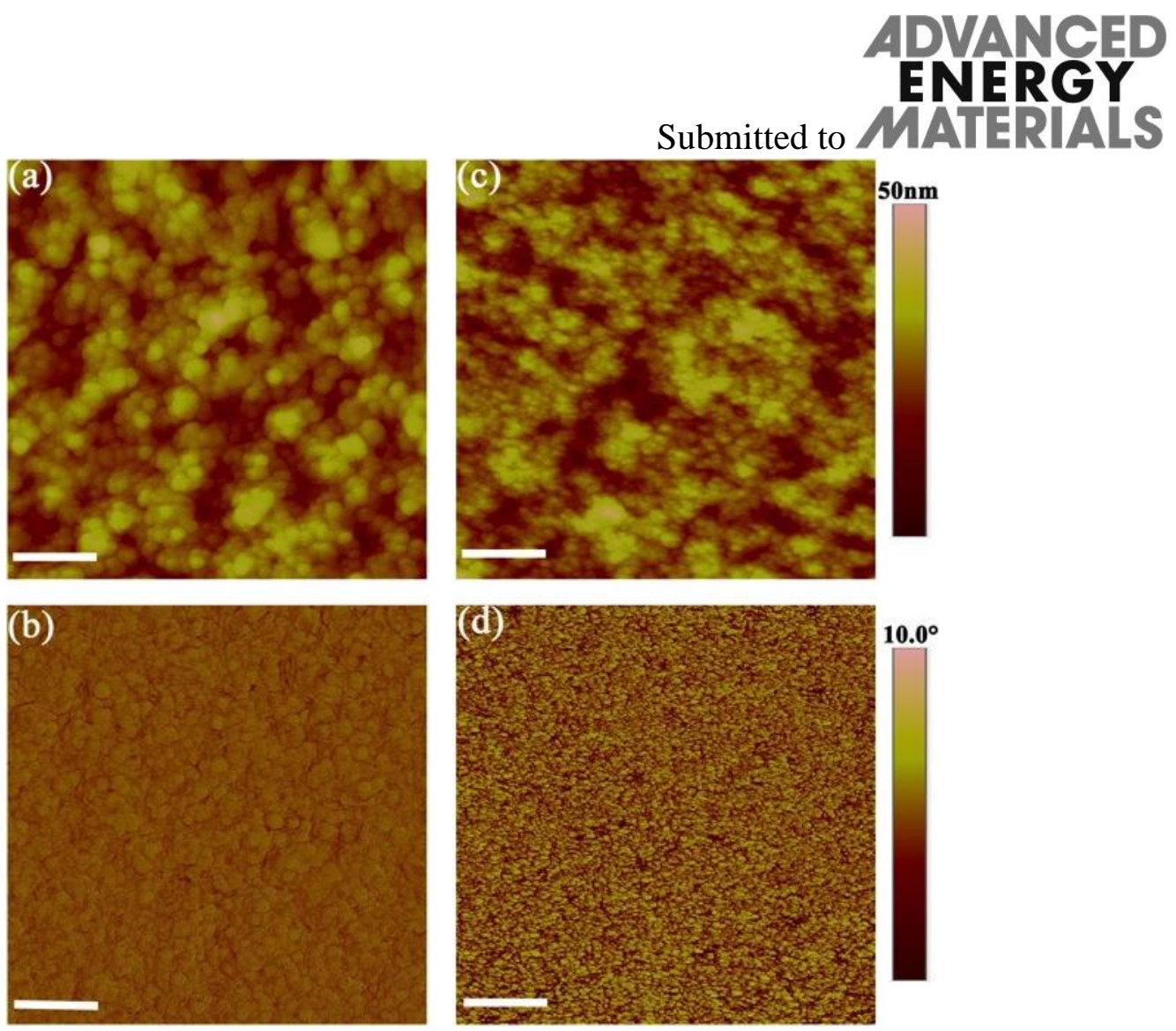

Figure S4. AFM characterizations. a) AFM topography and the corresponding phase image (b) of the P-ZnO films. c) AFM topography and the corresponding phase image (d) of the E$\mathrm{ZnO}$ films. The scan area for both images is $2 \mu \mathrm{m} \times 2 \mu \mathrm{m}$. Scale bar: $400 \mathrm{~nm}$. 

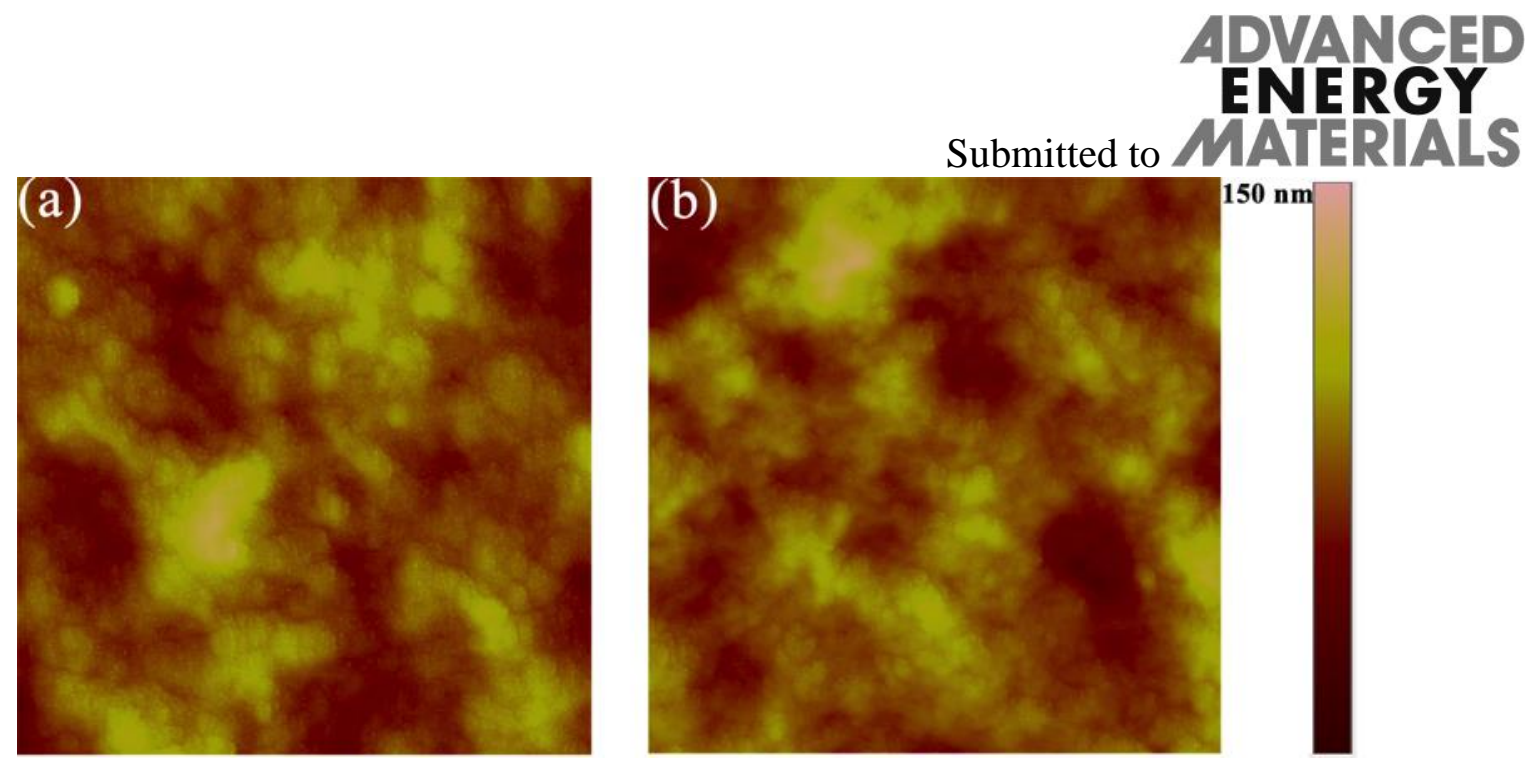

Figure S5. AFM $(5 \times 5 \mu \mathrm{m})$ topography images of $\mathrm{P} 3 \mathrm{HT}: \mathrm{PC}_{61} \mathrm{BM}$ blends deposited onto (a) the $\mathrm{P}-\mathrm{ZnO}$ film and (b) the $\mathrm{E}-\mathrm{ZnO}$ film, respectively. 
(a)

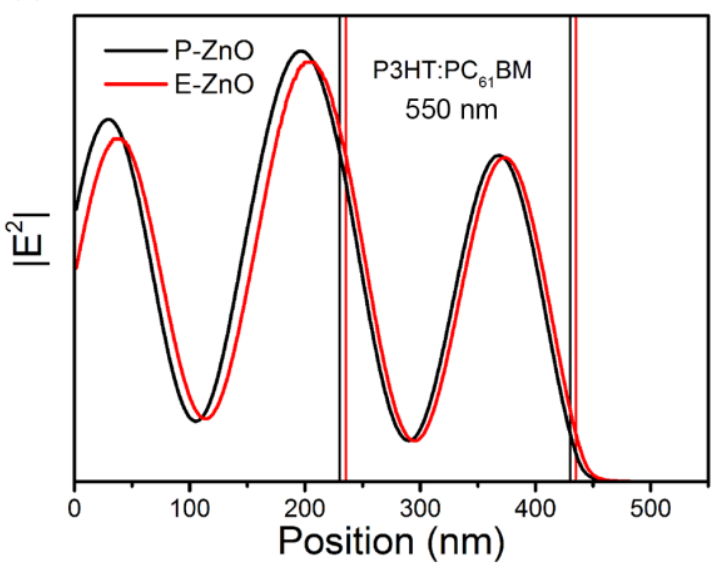

(b)

Submitted to MATERIALS

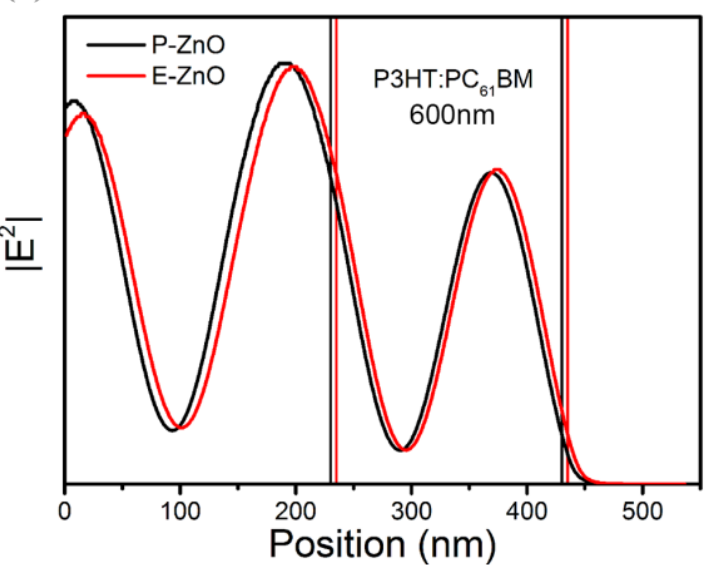

Figure S6. Optical field plot of $550 \mathrm{~nm}$ (a) and $600 \mathrm{~nm}$ (b) irradiation for a $200 \mathrm{~nm}$ P3HT:PC ${ }_{61} \mathrm{BM}$ layer for devices based on $\mathrm{P}-\mathrm{ZnO}$ and $\mathrm{E}-\mathrm{ZnO}$ interlayers. The transfer matrix approach was used to model the optical electric field distribution the active layer. ${ }^{[1]}$ The optical constants for ITO, $\mathrm{MoO}_{\mathrm{x}}$ and $\mathrm{Ag}$ are taken from the literatures. ${ }^{[2-4]}$ 


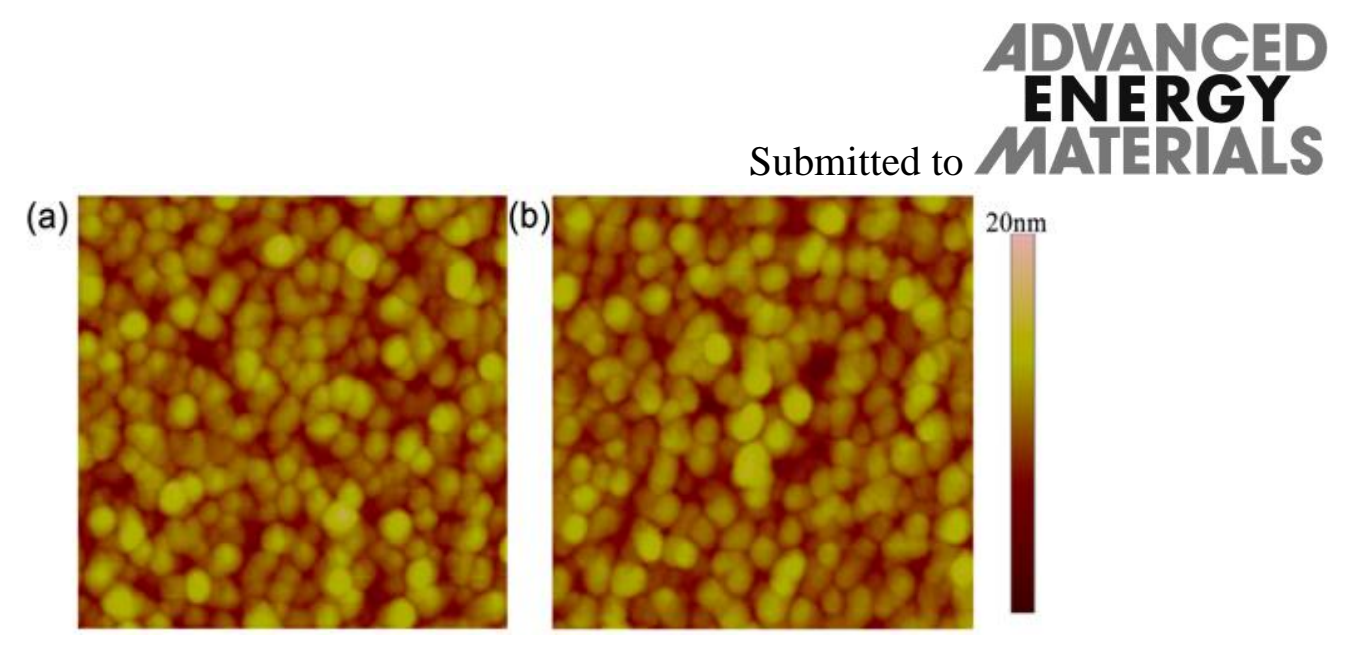

Figure S7. AFM $(2 \times 2 \mu \mathrm{m})$ topography images of TQ1:PC $71 \mathrm{BM}$ blends deposited onto (a) the $\mathrm{P}-\mathrm{ZnO}$ film and (b) the $\mathrm{E}-\mathrm{ZnO}$ film, respectively. 

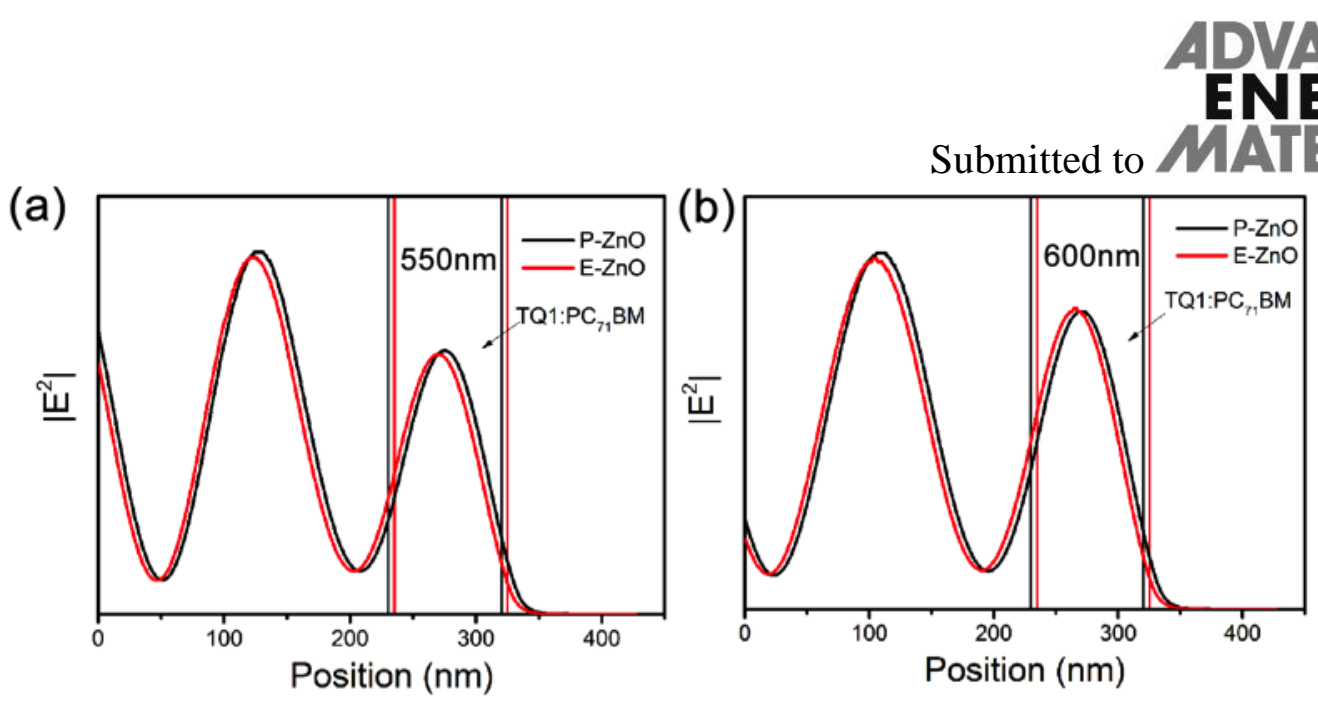

Figure S8. Optical field plot of $550 \mathrm{~nm}$ (a) and $600 \mathrm{~nm}$ (b) irradiation for a $90 \mathrm{~nm}$ TQ1:PC ${ }_{71} \mathrm{BM}$ layer for devices based on $\mathrm{P}-\mathrm{ZnO}$ and $\mathrm{E}-\mathrm{ZnO}$ interlayers, respectively. 
(a)

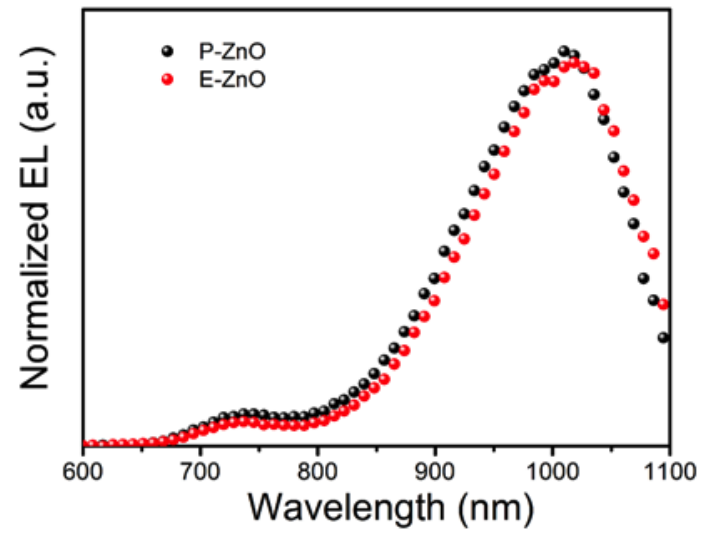

(b)

Submitted to MATERIALS

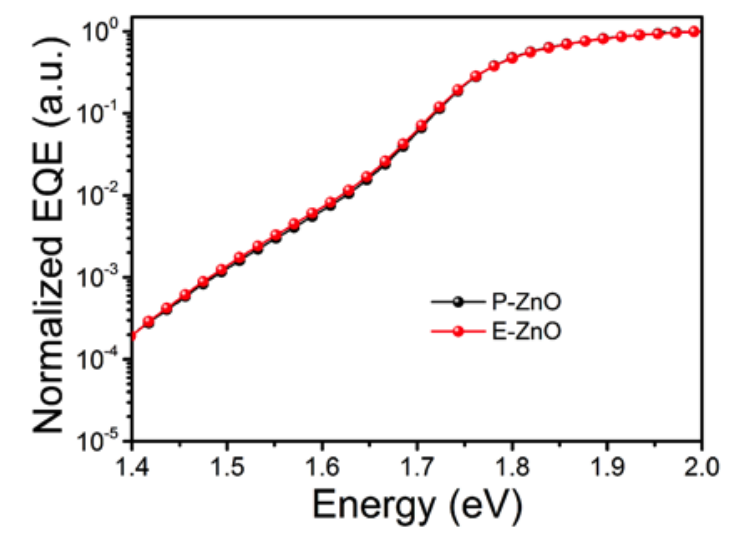

Figure S9. Normalized EL (a) and FTPS spectra (b) from inverted TQ1:PC 1 BM devices based on P-ZnO ETLs and E-ZnO ETLs, respectively.

References:

[1] L. A. A. Pettersson, L. S. Roman, O. Inganas, J. Appl. Phys. 1999, 86, 487-496.

[2] C. M. Ramsdale, N. C. Greenham, J. Phys. D: Appl. Phys. 2003, 36, L29.

[3] H. Hoppe, N. S. Sariciftci, D. Meissner, Molecular Crystals and Liquid Crystals 2002, 385, 113-119.

[4] S. Shao, J. Liu, J. Bergqvist, S. Shi, C. Veit, U. Würfel, Z. Xie, F. Zhang, Adv. Energy. Mater. 2013, 3, 349-355. 